\title{
A comparative analysis of energy dissipation and equivalent viscous damping of RC columns subjected to uniaxial and biaxial loading
}

\author{
Hugo Rodrigues ${ }^{\mathrm{a}, *}$, Humberto Varum ${ }^{\mathrm{a}}$, António Arêde ${ }^{\mathrm{b}}$, Aníbal Costa ${ }^{\mathrm{a}}$ \\ a Departamento de Engenharia Civil, Universidade de Aveiro, Portugal \\ ${ }^{\mathrm{b}}$ Departamento de Engenharia Civil, Faculdade de Engenharia, Universidade do Porto, Portugal
}

\section{A R T I C L E I N F O}

\section{Article history:}

Received 27 June 2011

Revised 6 October 2011

Accepted 2 November 2011

\section{Keywords:}

RC columns

Hysteretic behaviour

Biaxial testing

Energy dissipation

Viscous damping

\begin{abstract}
A B S T R A C T
The hysteretic behaviour of RC columns has been object of many experimental studies over the past years. However, the majority of these studies are focused on unidirectional loading. An experimental program was carried out where 24 columns were tested for different loading histories, under uniaxial and biaxial conditions. The experimental results are presented in this paper and are discussed in terms of global column behaviour, and particularly with regards to energy dissipation and damping capacity. The energy dissipation capacity of the columns was evaluated in terms of cumulative dissipated energy, comparing uniaxial and biaxial test results, and individual cycle dissipated energy. Ultimately, an equation relating the normalised dissipated energy with the displacement ductility is proposed. The equivalent viscous damping was analysed by comparing the uniaxial with biaxial test results, demonstrating the high influence of the load path in the biaxial response of RC columns. Proposals for estimating the equivalent viscous damping given by other authors are compared with the experimental results. Finally, simplified expressions are proposed to estimate equivalent viscous damping in RC columns under biaxial loading.
\end{abstract}

(c) 2011 Elsevier Ltd. All rights reserved.

\section{Introduction}

The behaviour of reinforced concrete (RC) elements subjected to axial loading in conjunction with cyclic biaxial bending is recognised as a very important research topic for building structures in earthquake prone regions. Previous experimental work agrees that biaxial horizontal cyclic loading can increase the strength and stiffness degradation, when compared to uniaxial loading. In addition, the failure mechanism of RC columns is found to be highly dependent on the load path and history and strongly affects both the ductility and energy dissipation capacity of the columns $[1,2]$.

Energy dissipation is a fundamental structural property of RC elements when subjected to seismic demands. For RC structures designed to accommodate damage without collapse due to a seismic event, the input energy can be dissipated through RC element's hysteretic response, without a significant reduction in strength [3]. Nonlinear static methods, for assessment or design, use energy dissipation capacity related parameters to evaluate the inelastic earthquake response of structures and to describe the strength and stiffness degradation of RC elements subjected to cyclic loading [4].

\footnotetext{
* Corresponding author. Tel.: +351 234370049; fax: +351 234370094 .

E-mail address: hrodrigues@ua.pt (H. Rodrigues).
}

Viscous damping is used to characterise the energy dissipation capacity of RC elements and is one of the key parameters for the application of displacement based design (DBD) methods [5]. DBD methods can be based on the substitute-structure concept, developed by Shibata and Sozen [6], which represents the structure intended for design or assessment purposes by the secant stiffness to maximum displacement response and equivalent viscous damping representing the combined effects of elastic and hysteretic damping [7].

Energy dissipation and the equivalent viscous damping have been correlated with displacement ductility for uniaxial stress. The current work intends to compare energy dissipation and equivalent viscous damping on RC columns subjected to uniaxial and biaxial loads. Finally, consideration is given to whether the available formulas relating viscous damping with the displacement ductility that have been proposed for uniaxial demands are applicable to biaxial loading.

\section{Test program}

In the experimental campaign were tested 24 rectangular $\mathrm{RC}$ columns with different types of geometric characteristic and reinforcement detailing and were cyclically tested for different loading histories with a constant axial force and under displacement controlled conditions. The column specimens are $1.70 \mathrm{~m}$ high and 
are cast in strong square concrete foundation blocks. The crosssection dimensions and the reinforcement detailing are presented in Fig. 1. The materials considered at the specimen design phase were a regular concrete class C35/45 for columns N01-N04 and C30/35 for columns N05-N24, with reinforcement steel grade of A400NR-SD, the average concrete strength obtained in tests on samples are summarised in Table 1.

Fig. 2 shows the setup adopted for the experimental testing including the two independent horizontal actuators to apply the lateral loads on the column specimen, one with a capacity of $500 \mathrm{kN}$ and $\pm 150 \mathrm{~mm}$ stroke and the other with a capacity of $200 \mathrm{kN}$ and $\pm 100 \mathrm{~mm}$ stroke. A vertical $700 \mathrm{kN}$ capacity actuator was used to apply the axial load. Two steel reaction frames and a concrete reaction wall form the reaction system for the three actuators. The column specimens and the reaction frames were fixed to the strong floor of the laboratory with prestressed steel bars to avoid sliding or overturning of the specimen during testing, or sliding of the reaction frame. Since the axial load actuator remains in the same position during the test while the column specimen laterally deflects, a sliding device is used (placed between the top-column and the actuator), which was built to minimise spurious friction effects. As stated previously, for all the specimens tested, a constant axial force was imposed, the values of which are included in Table 1 , for both absolute and normalised axial force.

In order to characterise the response of the column specimens, cyclic lateral displacements were imposed at the top of the column with steadily increasing demand levels. Three cycles were repeated for each lateral deformation demand level. This procedure allows for the understanding of the column's behaviour, a comparison between different tests and provides information for the development and calibration of numerical models, the following nominal peak displacement levels (in $\mathrm{mm}$ ) were considered: $3,5,10,4,12,15,7,20,25,30,35,40,45,50,55$, $60,65,70,75,80$.

\section{Global columns response}

From the analysis of the measured displacement and shear force paths (along the $X$ and $Y$ directions) are analysed. Due to the large number of tests, only a few examples of the results are presented in Figs. 3-5, but all the discussion refers to the results of the complete testing program, detailed information about the forcedisplacement results can be found in [2]. From the experimental campaign the main finding were:

- From the observation of the shear-drift curves, four main branches can be identified in their envelopes, corresponding to: (i) pre-cracking response; (ii) post-cracking until the reinforcement steel yields; (iii) a plateau or post-yield hardening zone; and (iv) a softening phase. These four stages are clear in both the uniaxial and biaxial tests. However, in the biaxial tests the plateau tends to be shorter and the softening is more pronounced, i.e. a more abrupt decay of the column strength is observed with increasing lateral deformation demands.

- The initial column stiffness in both directions it is not significantly affected by the biaxial load path.

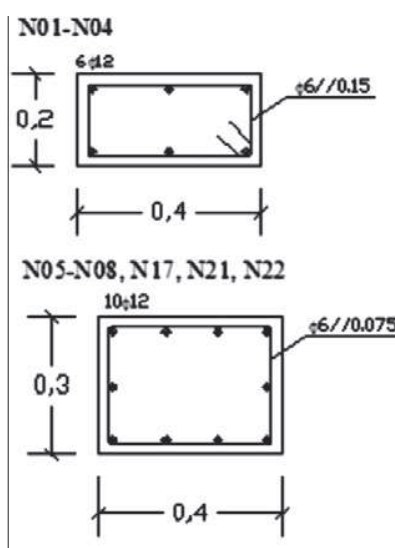

N09-N12, N18-N20

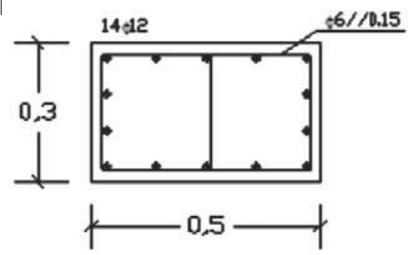

$\mathrm{N} 13-\mathrm{N} 16, \mathrm{~N} 23, \mathrm{~N} 24$

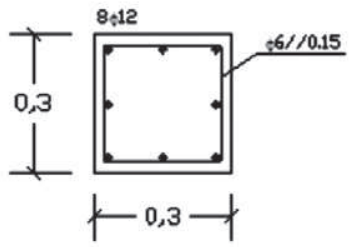

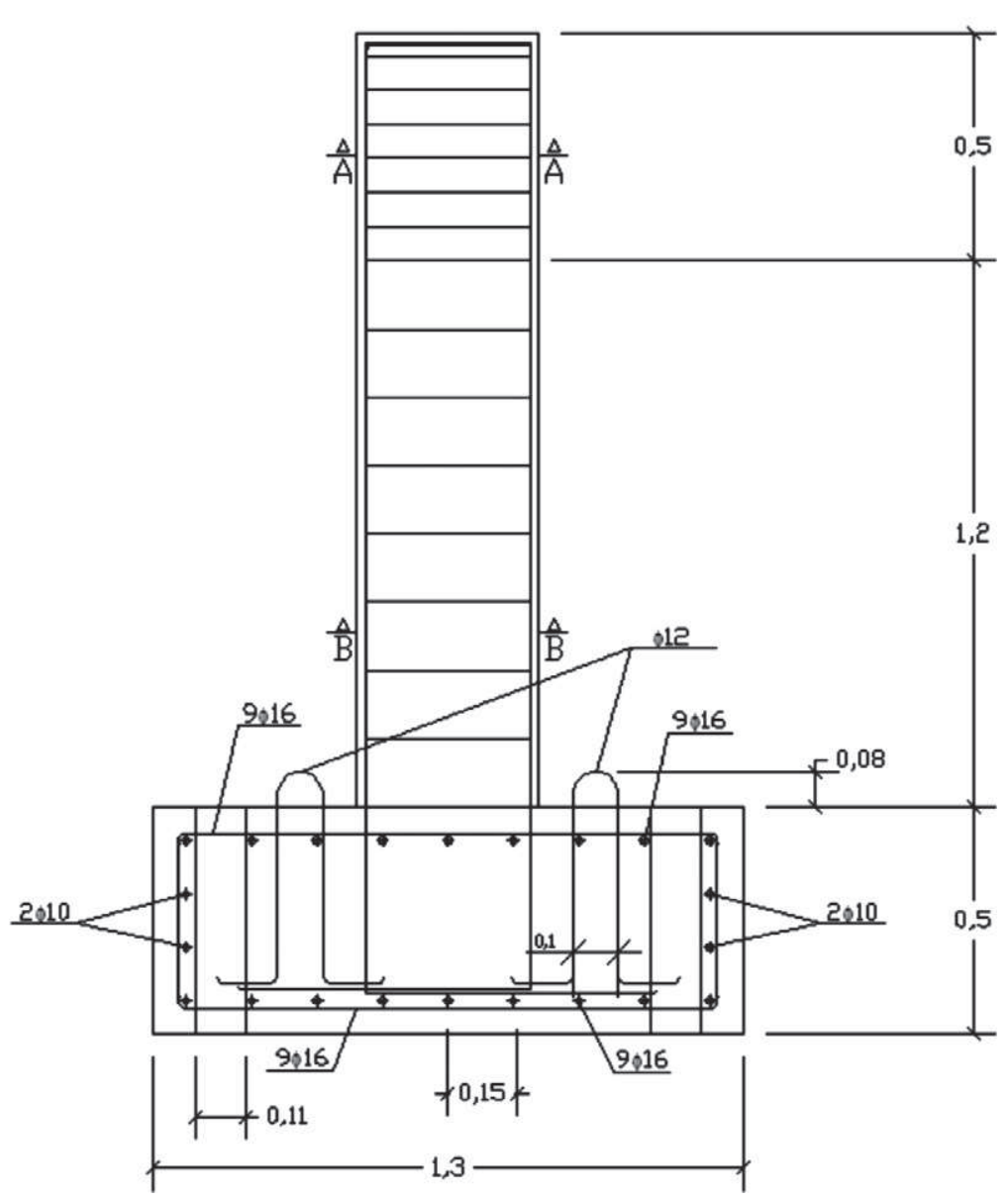

Fig. 1. RC column specimen dimensions and reinforcement detailing: cross-sections details and specimen dimensions and general scheme of the reinforcement layout. 
Table 1

Specimen specifications and loading characteristics.

\begin{tabular}{|c|c|c|c|c|c|c|}
\hline Series & Column & Geometry $(\mathrm{cm} \times \mathrm{cm})$ & $f_{\mathrm{cm}}(\mathrm{MPa})$ & $\mathrm{N}(\mathrm{kN})$ & $v \mathrm{~N} /\left(\mathrm{A}_{\mathrm{c}} \cdot \mathrm{f}_{\mathrm{cm}}\right)$ & Displacement path type \\
\hline 1 & $\begin{array}{l}\text { PB01-N01 } \\
\text { PB02-N02 } \\
\text { PB12-N03 } \\
\text { PB12-N04 }\end{array}$ & $20 \times 40$ & 48.35 & 170 & 0.04 & $\begin{array}{l}\text { Uniaxial strong } \\
\text { Uniaxial weak } \\
\text { Cruciform } \\
\text { Rhombus }\end{array}$ \\
\hline 2 & $\begin{array}{l}\text { PB01-N05 } \\
\text { PB02-N06 } \\
\text { PB12-N07 } \\
\text { PB12-N08 } \\
\text { PB12-N17 }\end{array}$ & $30 \times 40$ & 36.30 & $\begin{array}{l}300 \\
510\end{array}$ & 0.12 & $\begin{array}{l}\text { Uniaxial strong } \\
\text { Uniaxial weak } \\
\text { Rhombus } \\
\text { Quadrangular } \\
\text { Circular }\end{array}$ \\
\hline 3 & $\begin{array}{l}\text { PB01-N09 } \\
\text { PB02-N10 } \\
\text { PB12-N11 } \\
\text { PB12-N12 } \\
\text { PB12-N18 }\end{array}$ & $30 \times 50$ & 36.30 & 440 & 0.08 & $\begin{array}{l}\text { Uniaxial strong } \\
\text { Uniaxial weak } \\
\text { Rhombus } \\
\text { Quadrangular } \\
\text { Circular }\end{array}$ \\
\hline 4 & $\begin{array}{l}\text { PB01-N13 } \\
\text { PB12-N14 } \\
\text { PB12-N15 } \\
\text { PB12-N16 }\end{array}$ & $30 \times 30$ & 21.57 & 210 & 0.1 & $\begin{array}{l}\text { Uniaxial strong } \\
\text { Rhombus } \\
\text { Quadrangular } \\
\text { Circular }\end{array}$ \\
\hline 5 & $\begin{array}{l}\text { PB12-N19 } \\
\text { PB12-N20 }\end{array}$ & $30 \times 50$ & 43.14 & $\begin{array}{l}300 \\
600\end{array}$ & $\begin{array}{l}0.045 \\
0.09\end{array}$ & $\begin{array}{l}\text { Rhombus } \\
\text { Rhombus }\end{array}$ \\
\hline 6 & $\begin{array}{l}\text { PB12-N21 } \\
\text { PB12-N22 }\end{array}$ & $30 \times 40$ & 43.14 & 620 & 0.12 & $\begin{array}{l}\text { Rhombus } \\
\text { Quadrangular }\end{array}$ \\
\hline 7 & $\begin{array}{l}\text { PB12-N23 } \\
\text { PB12-N24 }\end{array}$ & $30 \times 30$ & 36.30 & 650 & 0.2 & $\begin{array}{l}\text { Rhombus } \\
\text { Quadrangular }\end{array}$ \\
\hline
\end{tabular}

$f_{\mathrm{cm}}$ - mean concrete compressive strength.

$N$ - axial load.

$v=N /\left(\mathrm{A}_{\mathrm{c}} \cdot f_{\mathrm{cm}}\right)-$ axial load ratio.

$A_{c}$ - area of the column cross section.

- As expected, when comparing the maximum strength in one specific direction of the columns for each biaxial test against the corresponding uniaxial test, lower values were obtained for all biaxial tests than uniaxial ones. The biaxial loading induces a $20-30 \%$ reduction of the maximum strength of the columns in their weak direction, $Y$, while reductions from 8 to $15 \%$ for the stronger direction, $X$.

- The ultimate ductility is significantly reduced in columns subjected to biaxial load paths.

- The strength degradation is practically zero, in the first loading cycles, increasing after displacement ductility demands of about 3. From the strength degradation analysis, more pronounced strength degradation was observed for biaxial tests when compared with corresponding uniaxial tests.

\section{Dissipated energy}

\subsection{Cumulative dissipated energy}

Bousias et al. [8] stated that the strong coupling between the two transverse directions of columns with biaxial loading produces an apparent reduction of strength and stiffness in each of the two transverse directions when considered separately, but also an increase in the hysteretic energy dissipation. This increase is due to the larger width of the hysteresis loops in the transverse direction in the presence of a non-zero force or deflection in the orthogonal direction.

Qiu et al. [9] claim that the accumulative hysteresis dissipation energy of a specimen under biaxial loading is apparently larger than that under unidirectional loading and is closely related to the loading position and path length.

The cumulative hysteretic dissipation energy was evaluated for all the tests, considering the area of each loading cycle in the $X$ and
$Y$ direction and then the total energy was calculated as the sum of these two parts, according to Eqs. (1)-(3).

$$
\begin{aligned}
& E d_{X}=\int F_{X} d_{X} \\
& E d_{Y}=\int F_{Y} d_{Y} \\
& E d_{\text {tot }}=\int F_{X} d_{X}+\int F_{Y} d_{Y}
\end{aligned}
$$

The results in terms of evolution of cumulative dissipated energy are presented in Fig. 6 for the uniaxial and biaxial tests. In Fig. 6, for each displacement amplitude level, the plotted value of dissipated energy corresponds to the end of the third cycle. For the quadrangular load path, the maximum displacement for each cycle occurs in the path corner. It is also presented in the plots, along with an additional series (dashed line) representing the sum of the dissipated energy in the uniaxial tests of the corresponding column cross-section. From the analysis of the results it can be concluded:

- Comparing the two uniaxial test results, as expected a lower energy dissipation was observed for the columns tested in its weakest direction, associated with the inferior column strength in this direction (15-20\% lower in the column of $30 \times 40 \mathrm{~cm}^{2}$ section and $60-80 \%$ in the column of $30 \times 50 \mathrm{~cm}^{2}$ section).

- The biaxial load paths induce larger amounts of dissipated energy than the correspondently uniaxial paths. However, the sum of the dissipated energy in the two unidirectional tests, the $X$ and $Y$ directions, leads to a dissipation energy evolution very close to that derived from the tests with rhombus and circular load paths.

- The results in terms of dissipated energy evolution for the cruciform, rhombus and circular load paths, is similar for all the columns tested. The circular load path induces an energy 


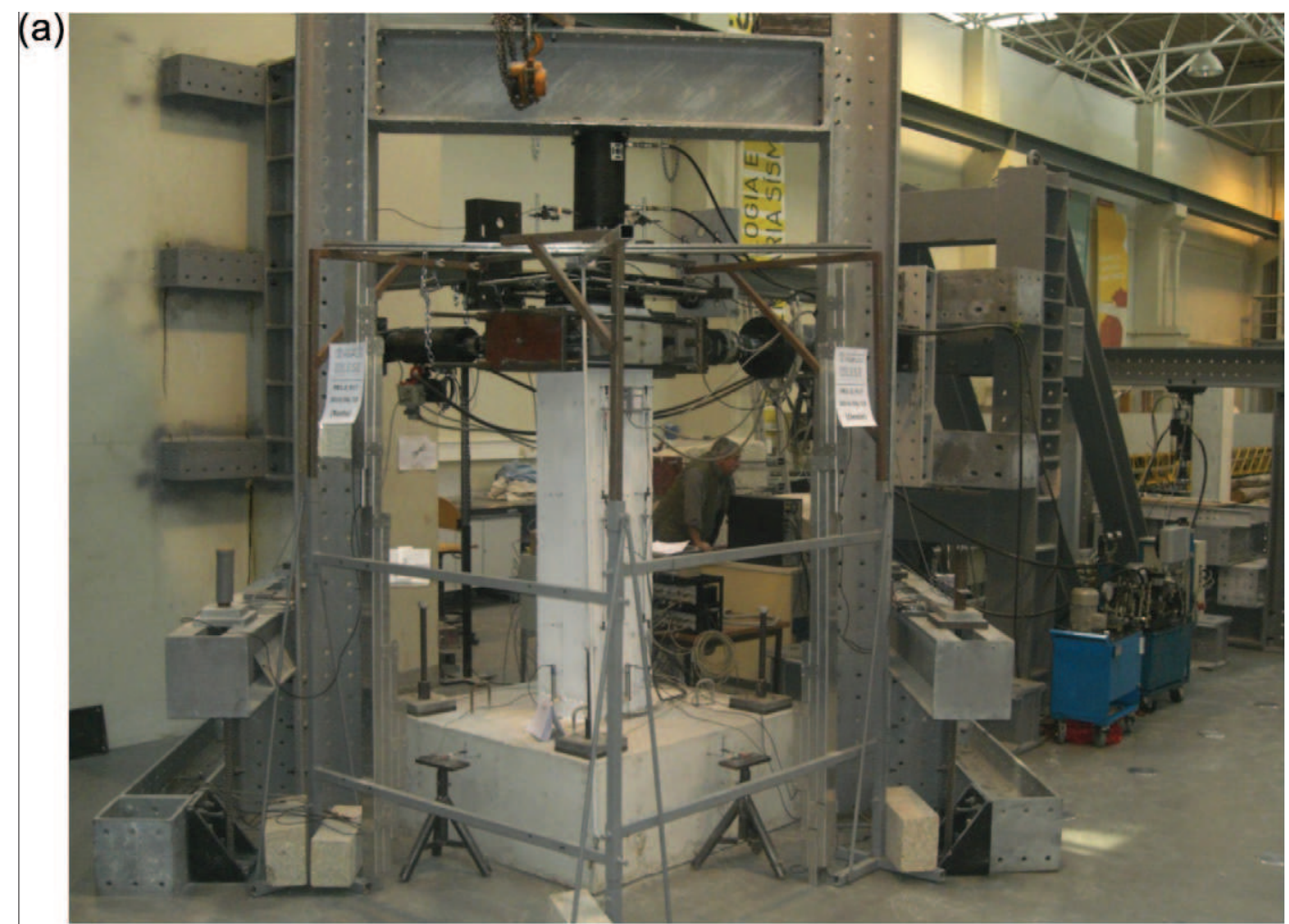

(b)

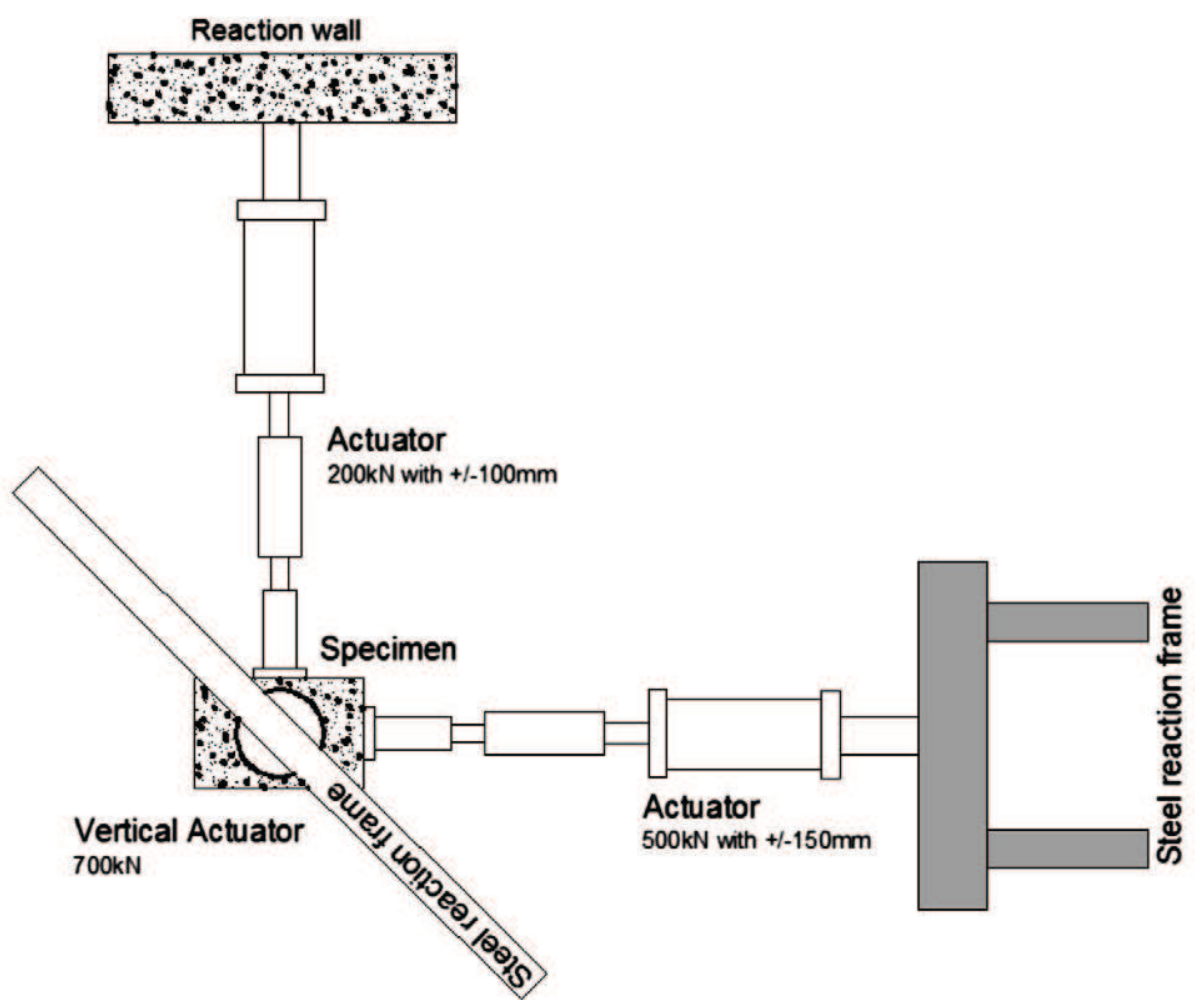

Fig. 2. Testing setup: (a) General view, (b) schematic layout (plan view)

dissipation approximately 20\% higher than the rhombus load path. Rhombus load paths dissipate $30 \%$ more energy than cruciform load paths.

- The quadrangular load path dissipates less energy than the other biaxial load paths. It should be recalled that the maximum drift demands on the quadrangular load path is reached in the path corner, corresponding to times the maximum drift reached along the $X$ and $Y$ axes. In accordance with this, the quadrangular load path dissipates 30-45\% less energy when compared to the rhombus load path. However, the quadrangular load path would dissipate 40-60\% more energy than the rhombus load path. 
है

Displacement ductility factor
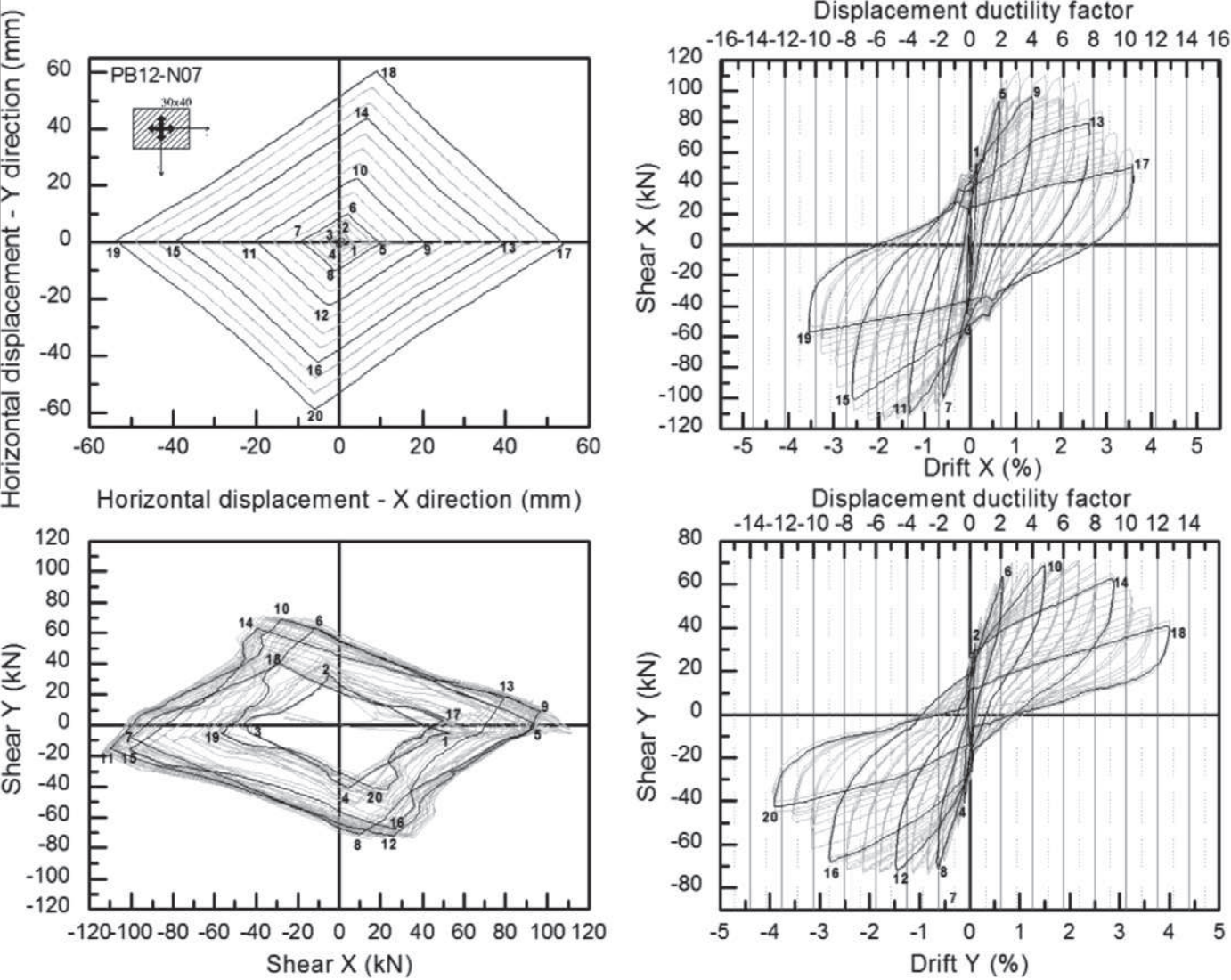

Displacement ductility factor

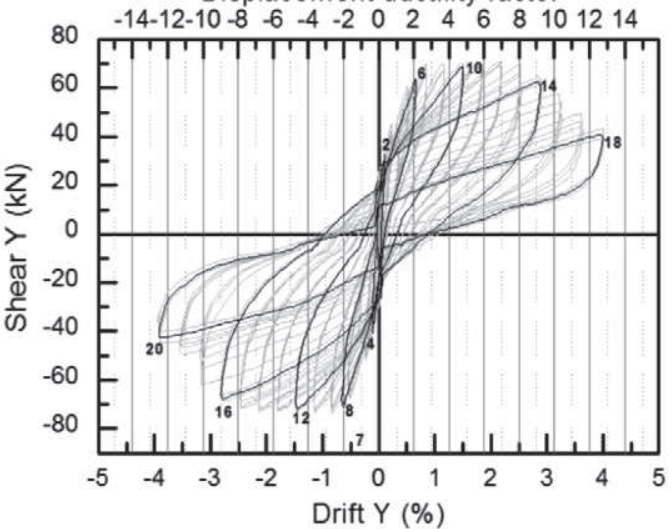

Fig. 3. Global results of rectangular column PB12-N07 for rhombus load path.
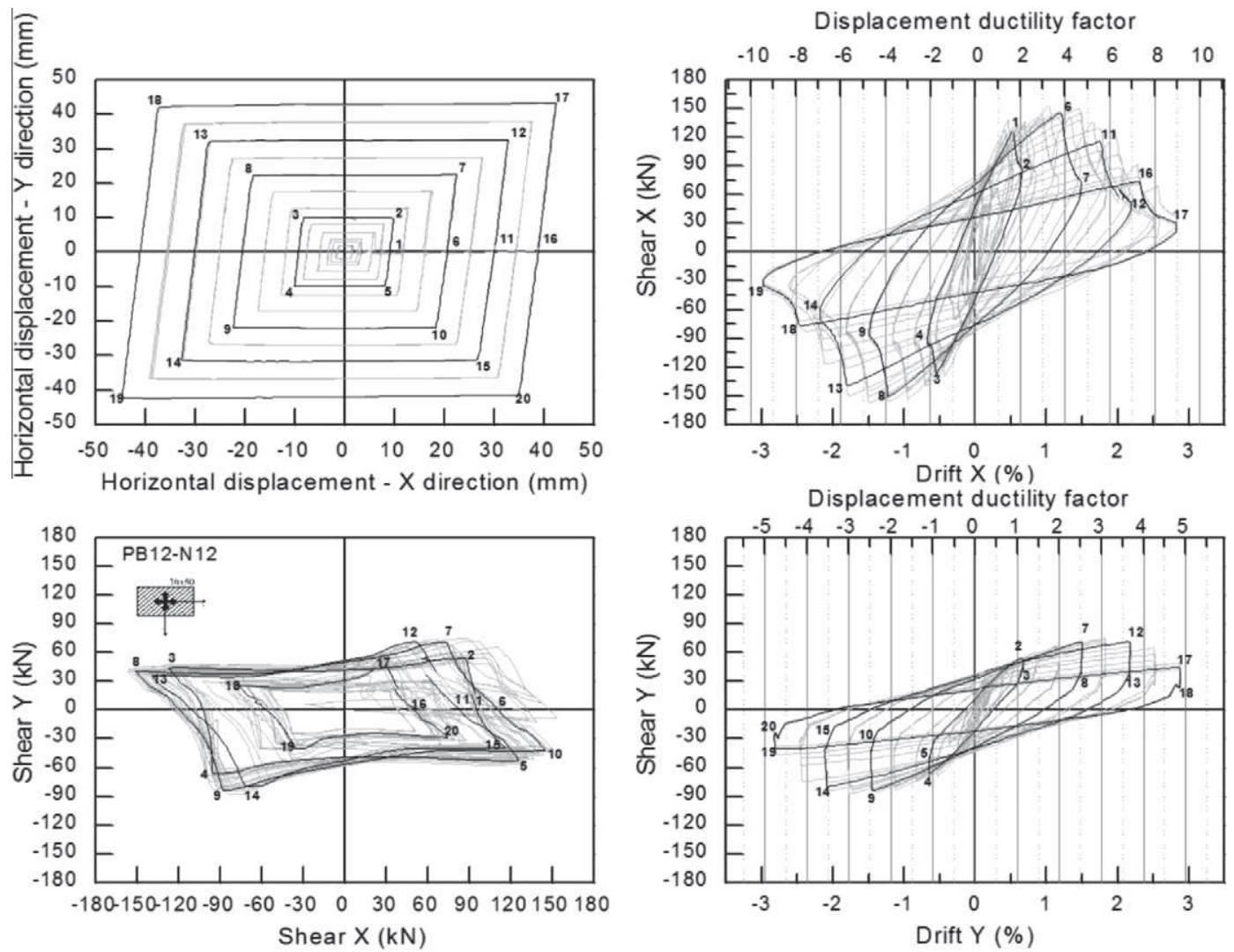

Fig. 4. Global results of rectangular column PB12-N12 for rectangular load path. 

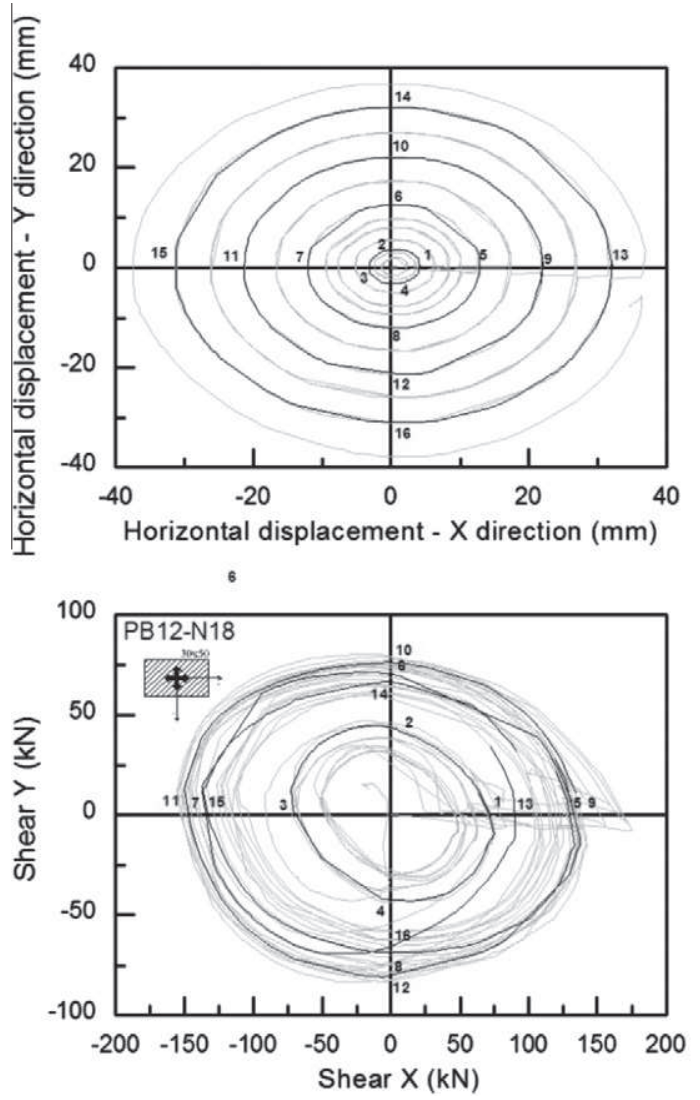

Displacement ductility factor

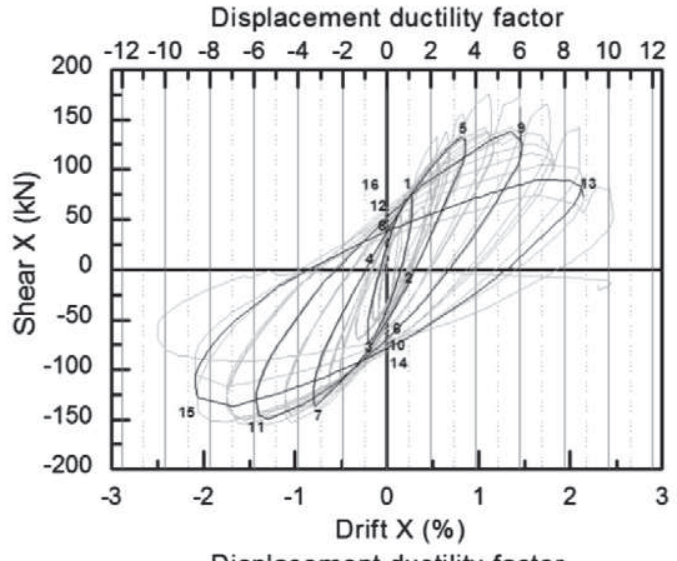

Displacement ductility factor

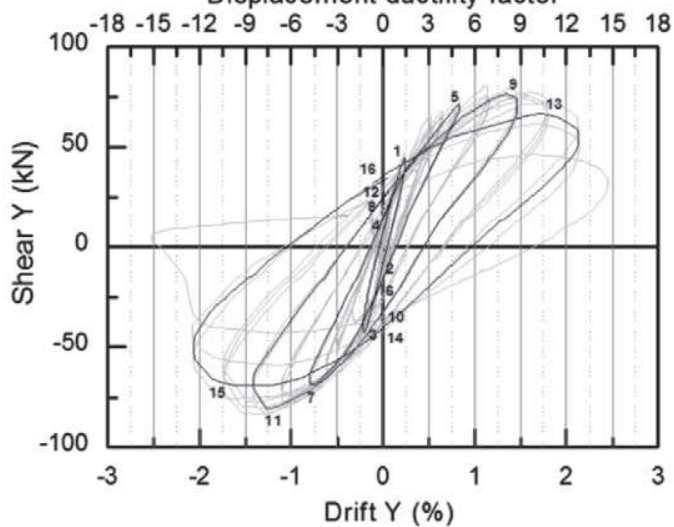

Fig. 5. Global results of rectangular column PB12-N12 for circular load path

- Comparing the dissipated energy of the biaxial load paths with the sum of the dissipated energy in the two unidirectional tests, the rhombus load path tends to dissipate more than $10-20 \%$ and the circular load path dissipates more than $20-40 \%$. The lower bound of these differences is found for the column with the square cross-section. This allows the conclusion that in the assessment and design of RC structures, not considering the bending interaction between each direction in the numerical models can introduce an error about of $10-40 \%$ in terms of energy dissipation.

\subsection{Individual cycle energy}

The energy dissipated for each individual loading cycle and the accumulated energy dissipation along each tested column was calculated. For purposes of correlation, the cycles for which relevant damage states occurred during the tests were also identified, namely the reinforcement bar buckling, conventional column collapse and bar failure. In Figs. 7 and 8 examples of the graphics obtained are presented. From the analysis of the results obtained for the 24 tested columns, the following can be concluded:

- In the first cycle of each peak displacement, higher energy dissipation is observed relative to the subsequent cycle with the same peak displacement. In the uniaxial tests, the reduction of the dissipated energy in the 2nd and 3rd cycles is about $10 \%$ of the energy dissipated in the 1 st cycle. This reduction is more pronounced for the biaxial load path, reaching $25 \%$. The damage induced during the first cycle reduces the stiffness and strength, reducing the energy dissipation capacity of the column in the second and third cycles (see examples in Figs. 7 and 8 ).
- A significant drop in the energy dissipation is observed after reaching the conventional rupture of the column. This effect is associated with the longitudinal bars buckling, which induces a high level of column strength degradation.

\subsection{Total dissipated energy until conventional collapse}

According to Ohno and Nishioka [10] the total dissipated energy of a RC column is independent of the loading path. This finding is in agreement with that of Tsuno and Park [11]. However, in both studies the columns tested were all square columns $\left(40 \times 40 \mathrm{~cm}^{2}\right.$ and $55 \times 55 \mathrm{~cm}^{2}$, respectively) and with axial load stresses between 0.98 and $1.96 \mathrm{MPa}$.

Figs. 9 and 10 compare the total dissipated energy obtained from the test results. This total dissipated energy corresponds to the energy dissipated from the start of the test until conventional rupture is reached, referring a strength decay of $20 \%$ relative to the maximum strength [12]. From the analysis of the results, the following observations can be drawn:

- For square columns (N13-N16) tested with a axial load stress of 2.33 MPa, the results obtained are in agreement with those reported by Ohno and Nishioka [10] and by Tsuno and Park [11], i.e. the dissipated energy up until conventional rupture is approximately the same (see Fig. 9) with differences lower than $10 \%$. However, for square columns (N23 and N24) with a higher level of axial load stress of 7.33 MPa this conclusion is not valid (see Fig. 9). The increase in axial load stress influences the total energy dissipated.

- For rectangular columns, the finding of Ohno and Nishioka [10] is not valid (see Fig. 9), the differences in strength and stiffness of the two orthogonal directions induce differences that cannot be dissociated from the biaxial coupling effect. 

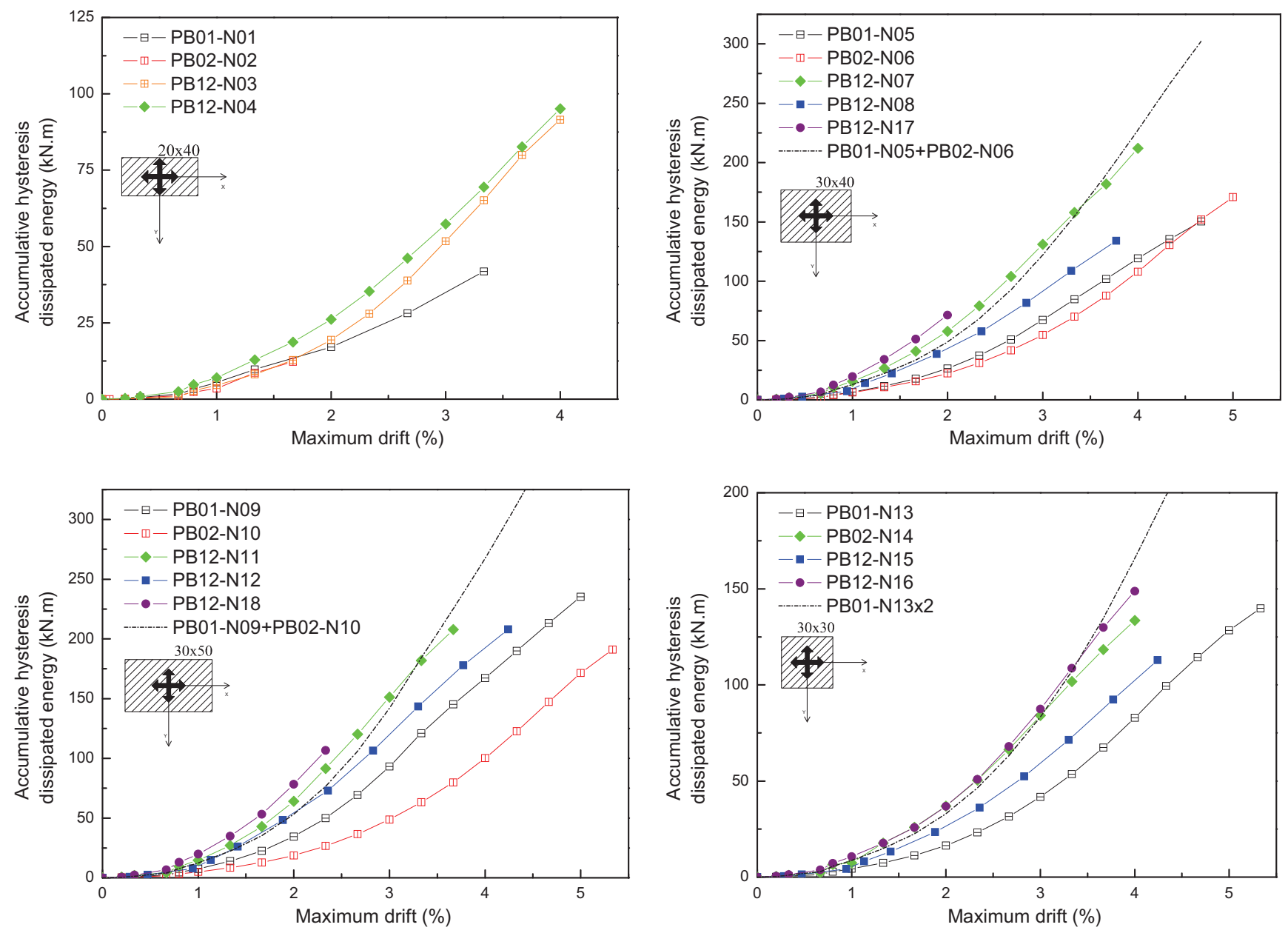

Fig. 6. Comparison of cumulative dissipated energy for columns with different load paths (uniaxial and biaxial loads).

- Uniaxial tests in rectangular columns tested, for the same loading history (comparing N05 with N06 and N09 with N10), show that the dissipated energy up until conventional rupture is dependent of the loading direction. The total dissipated energy in the weaker direction of the column at the point of rupture is $90 \%$ (N06) and 20\% (N10) higher than the corresponding results for the tests in the strong direction (N05 and N09).

- The axial load ratio shows to directly influence the total energy dissipation while the level of axial load force does not. In fact the response of similar rectangular columns of different concrete class tested for similar axial load ratios [N11 $(v=0.08$ and $N=300 \mathrm{kN})$ and N19 $(v=0.09$ and $N=600 \mathrm{kN})]$ result in dissipation that is approximately the same as the total energy. On the other hand, similar rectangular columns with different concrete classes tested for equal axial loading [N11 $(v=0.08)$ and $\mathrm{N} 20(v=0.045)$ both with $N=300 \mathrm{kN}$ ] demonstrated that the total energy dissipated is higher for the column with the lower axial load ratio (see Fig. 9).

- For square columns tested with different axial load ratios and different axial loads [N14 and N15 $(v=0.1)$ with $N=210 \mathrm{kN}$ and N23 and N24 $(v=0.2)$ with $N=650 \mathrm{kN}]$ similar findings were established, i.e. higher levels of axial load ratio present lower values of total dissipated energy (see Fig. 10).
- The non-repetition of the cycles, for the same load path considered in columns N21 and N22 when compared with columns N7 and N8 (see Fig. 11), increase the total dissipated energy (10$20 \%$ ) until reaching conventional rupture.

\subsection{Normalised dissipated energy vs. displacement ductility}

As stated by Elmenshawi and Brown [3], the relation between a RC element's displacement ductility and dissipated energy is complex due to the sensitivity of both factors to the element variables. For each column tested, the calculated energy dissipation evolution was normalised with the total dissipated energy until the first yield point $\left(E_{y}\right)$ until the column conventional failure, i.e. for a strength decay of $20 \%$ relative to the maximum strength.

In Fig. 12, the evolution of the normalised dissipated energy as a function of the corresponding displacement ductility for the tested columns is represented. Results from the uniaxial and biaxial tests are represented with different mark filling.

The best-fit power correlation curve for all tests results (uniaxial and biaxial) is shown in Fig. 12 and is given by expression 4 .

$\frac{E_{\text {cum }}}{E_{y}}=0.64 \mu^{2.1}$

This expression is very similar to that obtained by best-fit correlation to the test results from the uniaxial and biaxial loading separately. 

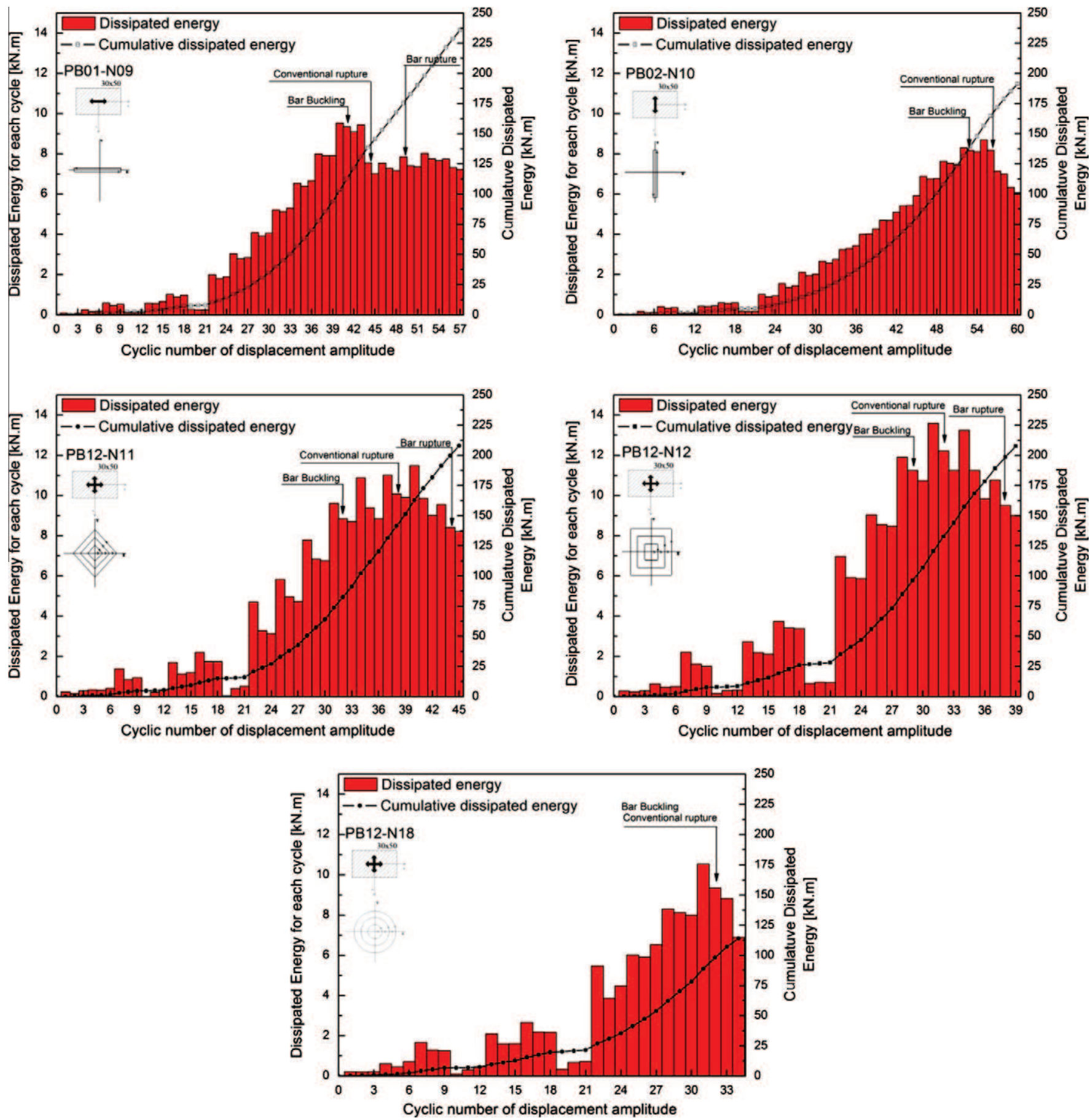

Fig. 7. Individual cycle energy and cumulative dissipated energy for a rectangular columns (N09 to N12 and N18).

As given by the proposed equation, for a displacement ductility of 4 (corresponding to the minimum required ductility to withstand a severe earthquake), the corresponding normalised dissipated energy estimated is 12. Elmenshawi and Brown [3] and Nmai and Darwin [13] have investigated this relationship for beams (with zero axial force), proposing similar equations. From this expression a value of normalised dissipated energy for the same displacement ductility is 3 time higher, around 35. This difference can be associated with the axial loading levels.

As stated by Darwin and Nmai [14], the proposed equations need to be verified with other experimental results. A validated expression can be very useful to estimate the dissipated energy in the seismic design of RC elements in accordance with international codes such as ACI 318-08 [15].

\section{Equivalent viscous damping ratio}

\subsection{Evaluation of equivalent damping from experimental results}

The equivalent damping depends on the structural displacement ductility demand and the location of the plastic hinges in the elements [16]. It may be interpreted as the superposition of the elastic and hysteretic damping as shown in Expression 5, 

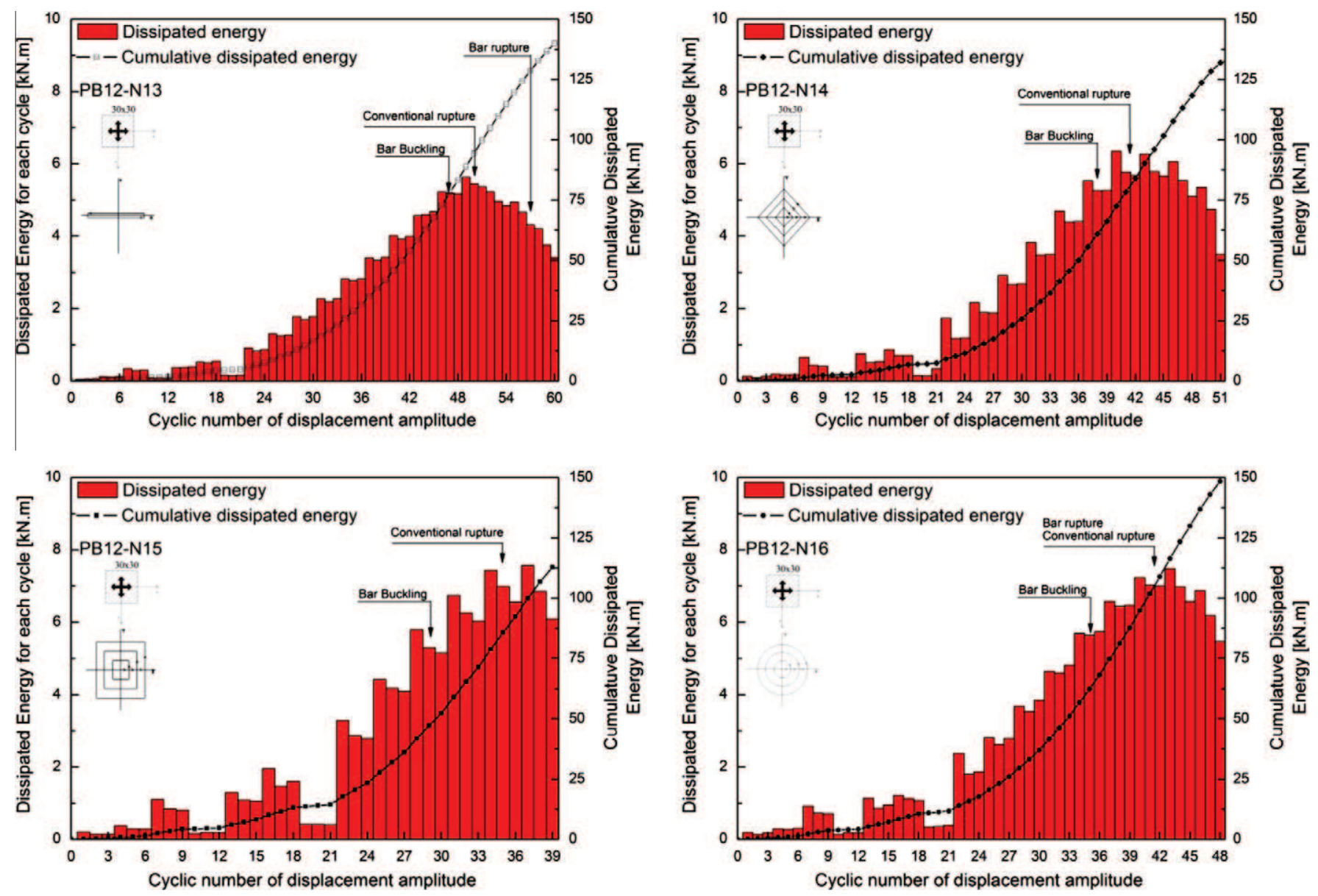

Fig. 8. Individual cycle energy and cumulative dissipated energy for square columns (N13-N16).

wherein the symbol "+" stands for superposition rather than a trivial summation.

$\xi_{\text {eq }}=\xi_{\text {el }}^{\prime \prime}+{ }^{\prime \prime} \xi_{\text {hyst }}$

It is widely accepted that, for typical RC structures, the elastic damping ratio $\left(\xi_{e l}\right)$ is generally taken as $5 \%$ of the critical damping [17] and computed proportionally either to the initial (or tangent) stiffness, or to the mass, or to both stiffness and mass. By contrast, the hysteretic damping ( $\xi_{\text {hyst }}$ ) depends essentially on the postyielding characteristics of the element and it is normally taken defined proportionally to the secant stiffness [18], which is directly related to the hysteretic rules generally calibrated to represent the structural response in the inelastic phase [19]. Therefore, both damping types should not be directly summed up.

For a perfectly symmetric hysteretic response and corresponding closed loop (as in the case of pure harmonic loading), the hysteretic equivalent damping coefficient $\left(\xi_{\text {hyst }}\right)$ can be given accurately given by the well known Expression 6, where $E_{D}$ stands for the dissipated energy within a given cycle, $A_{\text {loop }}$ is the area of the corresponding closed loop in the total restoring forcedisplacement diagram and $E_{S O}$ is the "elastic" strain energy associated with the maximum force $\left(F_{\max }\right)$ and displacement $\left(D_{\max }\right)$ reached in the loop.

$\xi_{\text {hyst }}=\frac{E_{D}}{4 \pi E_{S 0}}=\frac{A_{\text {loop }}}{2 \pi F_{\max } D_{\max }}$

However, in the case of seismic loads or even for tests performed under displacement controlled conditions, some asymmetries can be observed and the loops may not be closed, which means that the direct use of Expression 6 is less appropriate.
Therefore, based on the work of Jacobsen [20] and according to the procedure proposed by Varum [21], the equivalent hysteretic damping can be evaluated for each half-cycle of the forcedisplacement curves as shown in Fig. 13 and described next:

- First, each half-cycle is identified, delimited by a pair of zero-force points.

- For each force-displacement half-cycle, the maximum generalised force $\left(F_{\max }\right)$ and the maximum generalised displacement $\left(D_{\max }\right)$ are evaluated, which allows calculating the "elastic" strain energy $\left(E_{S O}\right)$.

- For each half-cycle, the dissipated energy $\left(E_{D}\right)$ is computed by performing the integral of the force-displacement curve leading to the $A_{\text {half-loop }}$ value.

- Finally, the equivalent damping ratio $\left(\xi_{\text {eq }}\right)$ is computed with the Eq. (7), for each half-cycle.

$\xi_{\text {hyst }}=\frac{1}{\pi} \frac{A_{\text {half-loop }}}{F_{\max } D_{\max }}$

This evaluation may be used as a first approach for estimating the hysteretic damping, and for comparing the tested columns with different cross sections and for different load paths. However, as pointed out by Dwairi et al. [22], it should be noted that an overestimation of the equivalent damping may be obtained, when it is computed proportionally to the dissipated energy and the ductility level.

For each column tested, with a uniaxial or biaxial load path, the equivalent damping was calculated, according to the methodology presented, for each independent direction $(X$ and $Y$ ) from the 

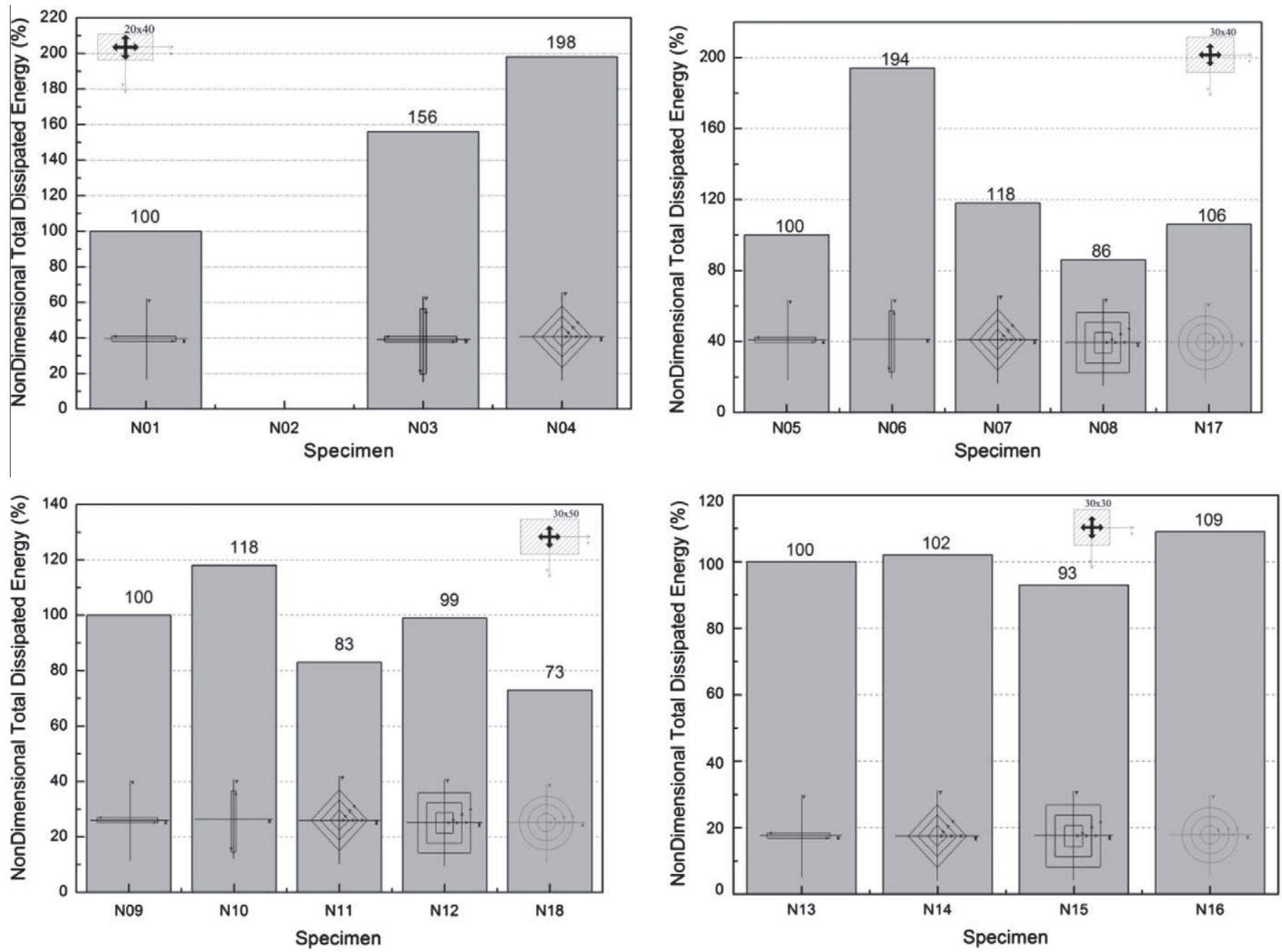

Fig. 9. Evaluation of total energy dissipated of columns tested for uniaxial and biaxial loads (with different load paths).
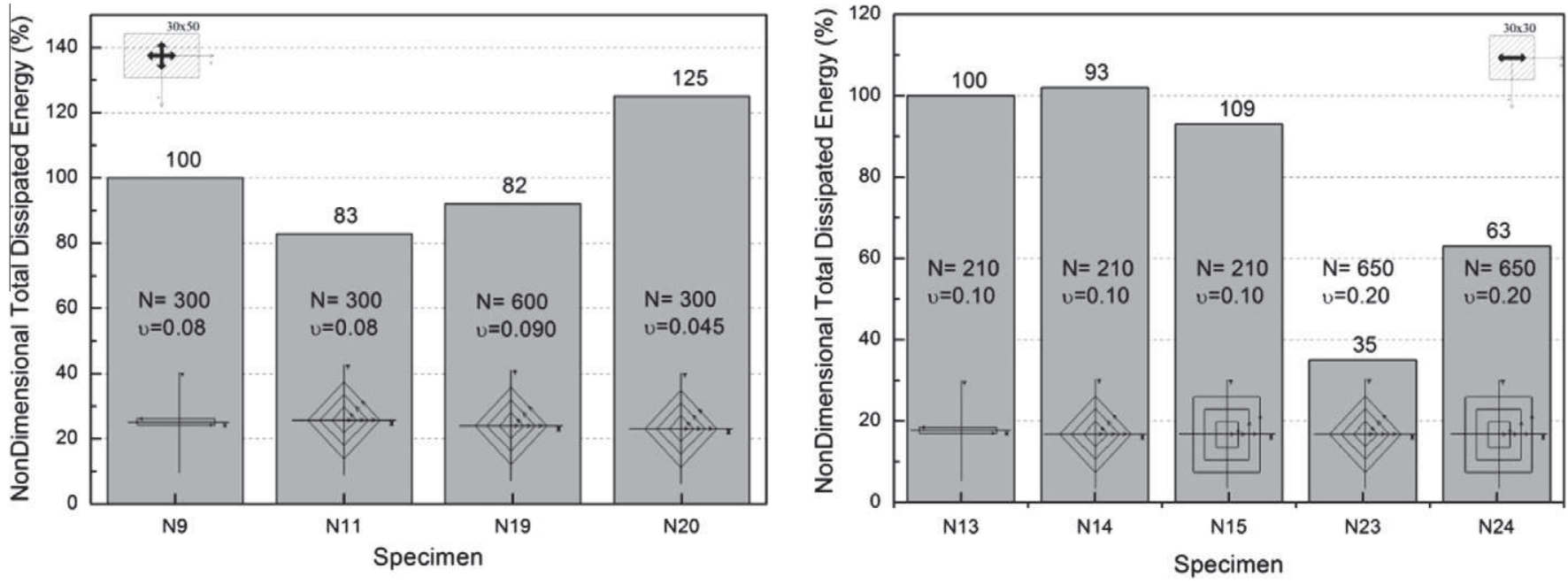

Fig. 10. Evaluation of total energy dissipated for columns with different axial loads.

shear-drift curves. Subsequently a best-fit logarithmic curve was adjusted for each tested column in terms of equivalent damping as a function of maximum ductility demand (see an example in Fig. 14 for column N13).
- In Figs. 15-17 the best-fit logarithmic curves obtained for each tested column for each direction ( $X$ and $Y$ ) are compared and the equations and the correlation factors $\left(R^{2}\right)$ are summarised in Table 2. In Fig. 15 the results for different load paths (uniaxial 


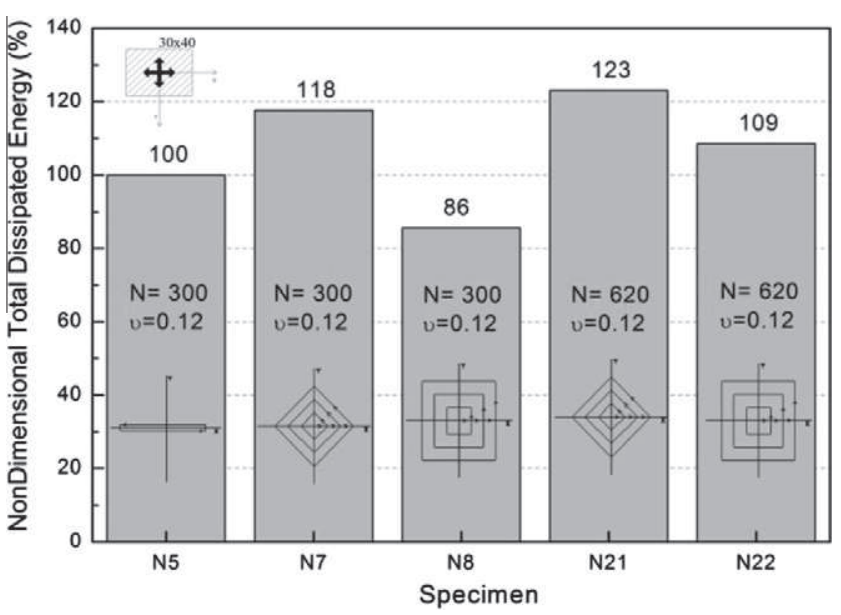

Fig. 11. Evaluation of total energy dissipated for columns with and without cycle repetition.

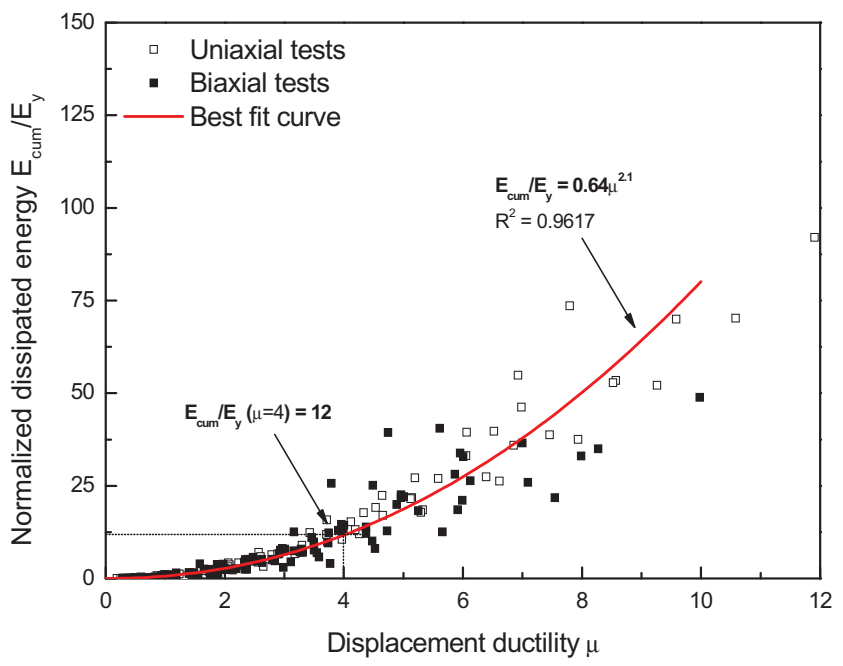

Fig. 12. Normalised dissipated energy vs. displacement ductility.

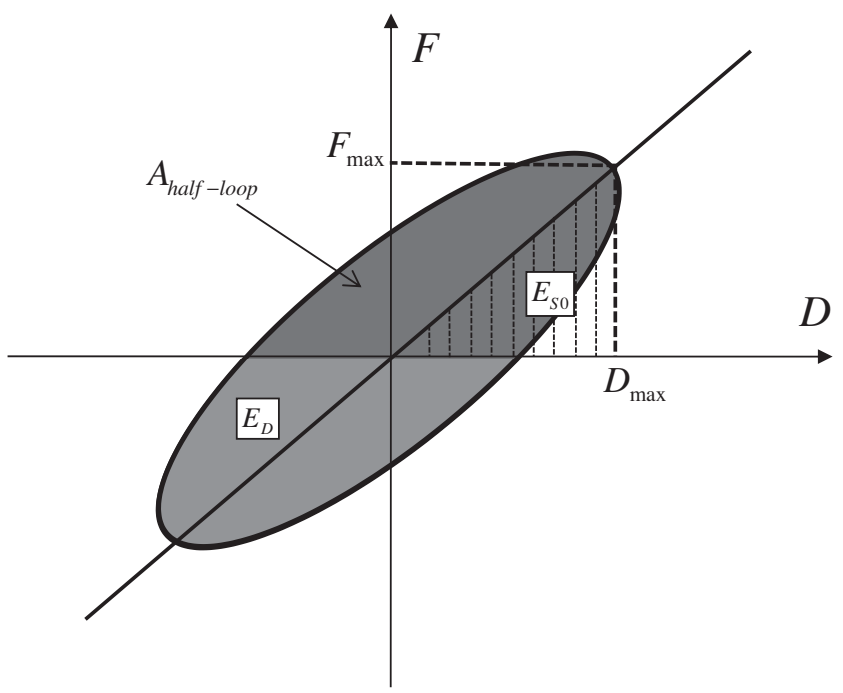

Fig. 13. Damping for a hysteretic half-cycle.

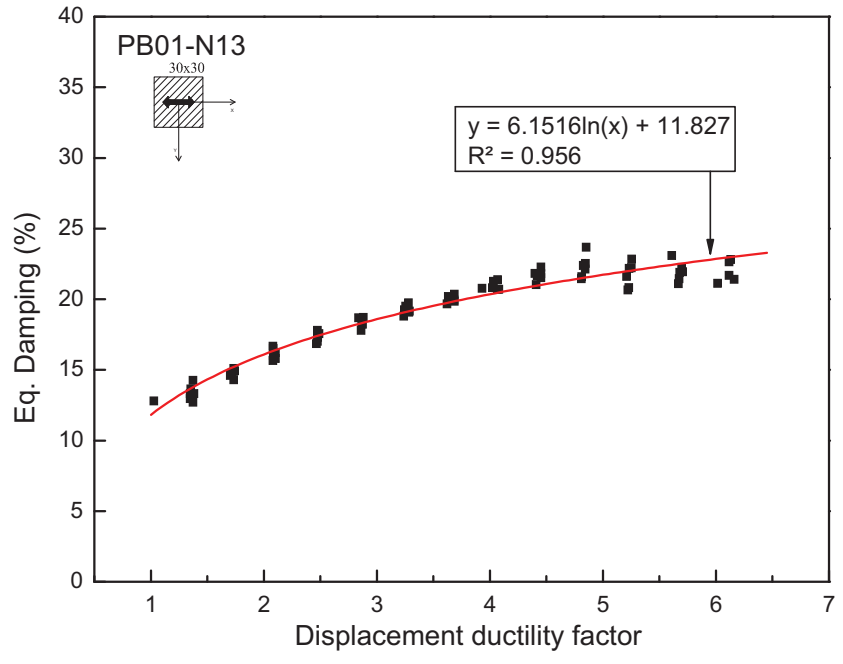

Fig. 14. Equivalent damping vs. maximum ductility demand and best-fit logarithmic curves from column N13.

and biaxial) are compared. Fig. 16 highlights the influence of the axial load and axial load ratio on the damping. Finally, in Fig. 17 the influence of the cycle repetition on damping is analysed. From the analysis of the results in terms of the equivalent damping function of ductility it is possible to conclude that the obtained values are higher than expected, due to the calculation procedure used that tends to overestimate the equivalent damping, as discussed in [22]. However the comparison of the equivalent damping calculated for each tested column and for the different load paths allows concluding that the logarithmic best-fit curve correlates well with test results for the uniaxial tests, but lower correlation factors were found from biaxial test results (see Table 2 ).

- A significant influence of the load path on the equivalent damping was found (see Fig. 15). Generally, the biaxial load path induces higher equivalent damping values when compared with the uniaxial tests.

- The quadrangular load path presents a higher equivalent damping than that obtained from the other biaxial load paths.

- From Fig. 15 can be concluded that higher values of axial load tend to induce larger equivalent damping in the strong direction $(X)$, but no influence was found for the column's weak direction $(Y)$.

- The equivalent damping results are compared in Fig. 16, for biaxial rhombus and quadrangular tests with and without repetition of cycles for the same axial load ratio. The results obtained are very similar.

\subsection{Empirical proposals for equivalent damping in $R C$ elements under uniaxial loadings}

Different proposals for the equivalent damping of RC elements and structures can be found in the literature, including the works of Priestley et al. [16,17], Rosenblueth and Hererra [23], Gulkan and Sozen [24], Kowalsky [25], among others. Blandon [7] developed an extensive review and study of the existing proposals for all type of elements. The more frequently used equations for the prediction of equivalent damping $(\xi)$ of RC columns as a function of ductility $(\mu)$ are:

- Rosenblueth and Hererra [23], based on the response of a Bilinear elasto-plastic system, where $r$ is the post yield stiffness coefficient, 

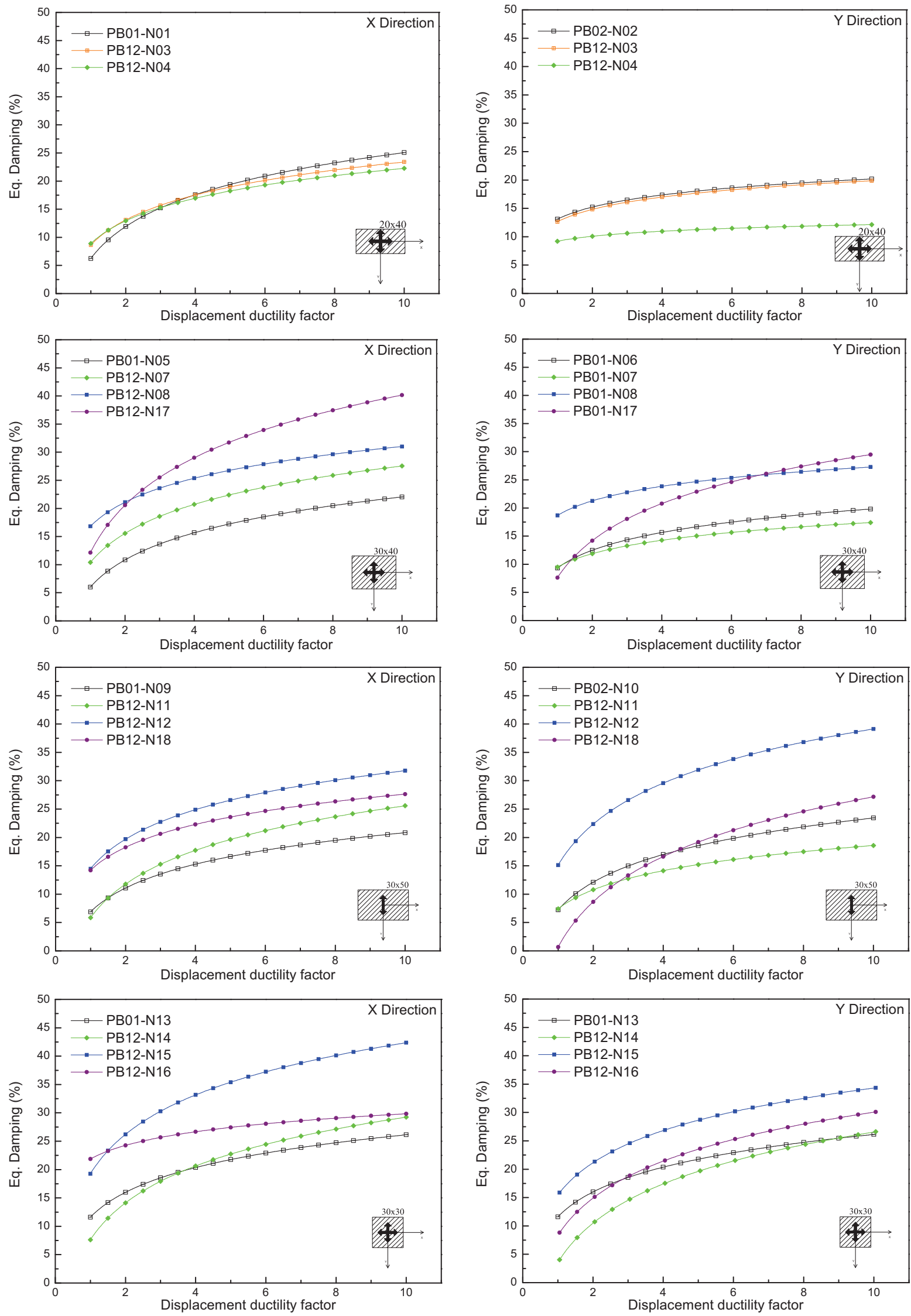

Fig. 15. Best-fit equivalent damping vs. maximum ductility demand for different levels of load paths. 

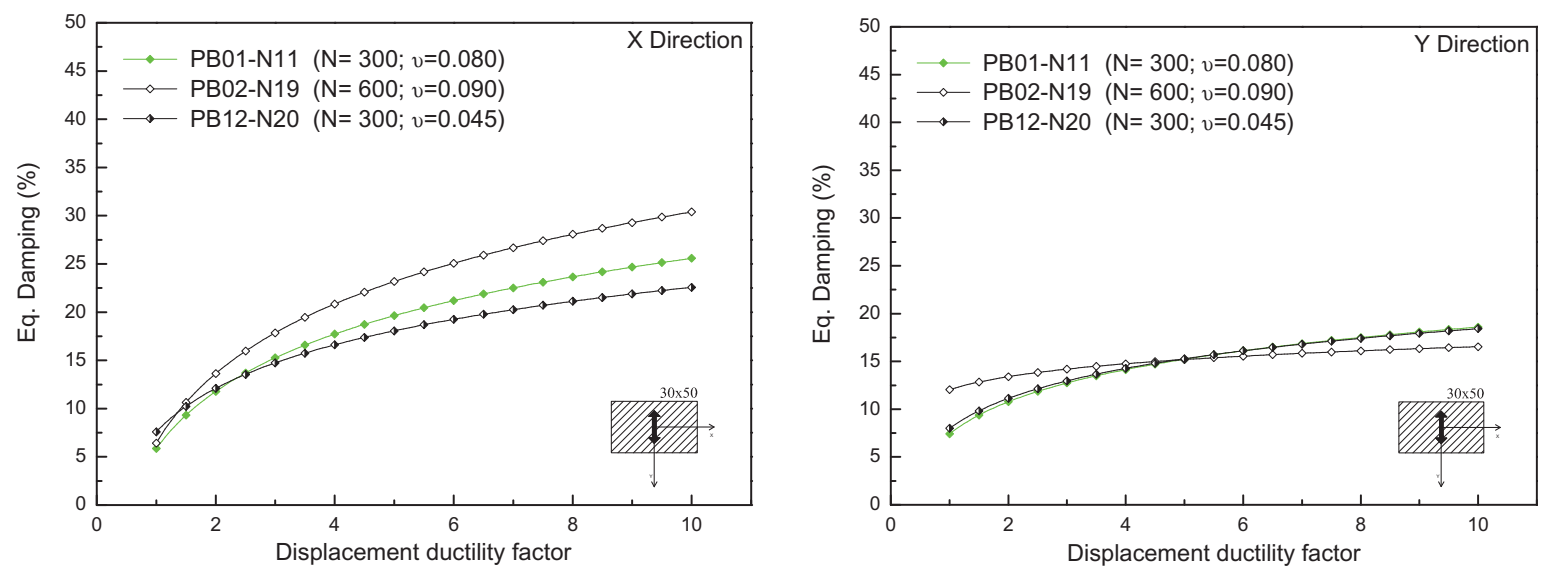

Fig. 16. Best-fit equivalent damping vs. maximum ductility demand for different levels of axial Force.
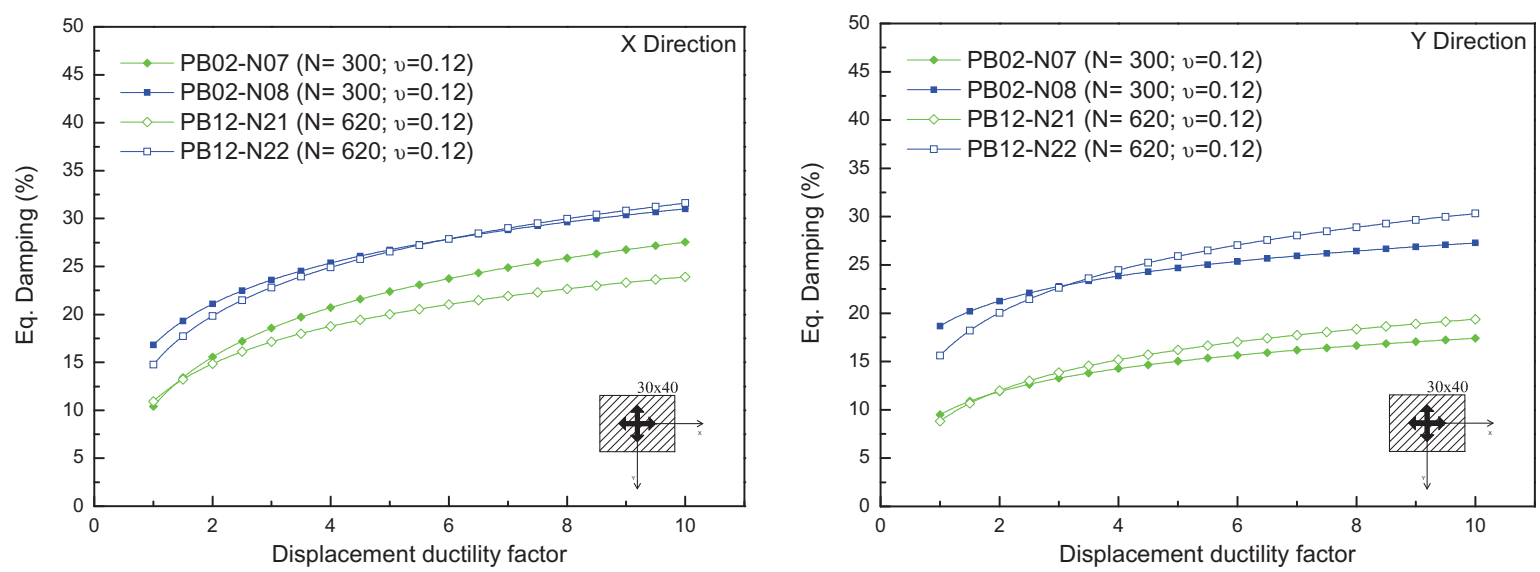

Fig. 17. Best-fit equivalent damping vs. maximum ductility demand for the same load path with and without cyclic repetition.

$$
\xi_{e q}=\xi_{0}+\frac{2}{\pi}\left[\frac{(1-r)(\mu-1)}{\mu-r \mu+r \mu^{2}}\right]
$$

- Gulkan and Sozen [24], based on the Takeda model,

$$
\xi_{\text {eq }}=\xi_{0}+0.2\left[1-\frac{1}{\sqrt{\mu}}\right]
$$

- Kowalsky [25], based on the Takeda model with a $\alpha=0.5$ and $\beta=0$, where $\mathrm{r}$ is the post yield stiffness coefficient,

$$
\xi_{\text {eq }}=\xi_{0}+\frac{1}{\pi}\left[1-\frac{1-r}{\sqrt{\mu}}-r \sqrt{\mu}\right]
$$

- Stojadinovic and Thewalt [26], developed the following expression based on regression analysis for experimental results of columns and beams tested under quasi-static cyclic loading conditions:

$$
\xi_{\text {eq }}= \begin{cases}4.7 & \mu<1.0 \\ -0.4 \mu^{2}+7.1 \mu-2 & \text { otherwise }\end{cases}
$$

- Lu et al. [27], based their formula on shaking table test results for RC frames:

$$
\xi_{\text {eq }}=\sqrt{100-6.5(\mu-5)^{2}} \text { for } \mu<5.0
$$

- Priestley [17], for concrete columns and walls

$$
\xi_{\text {eq }}=5+\frac{95}{\pi}\left[1-\frac{1}{\sqrt{\mu}}\right]
$$

- Dwairi and Kowalsky [28], where $C$ is dependent on the hysteresis rule

$$
\xi_{\text {eq }}=C\left[\frac{\mu-1}{\mu \pi}\right]
$$

- Priestley et al. [17], for concrete framed buildings

$$
\xi_{e q}=0.05+0.565\left[\frac{\mu-1}{\mu \pi}\right]
$$

The results given by the equations presented were compared with the experimental results obtained from the uniaxial tests. In order to evaluate the accuracy of the empirical expressions presented, the correlation factor between the predicted values and experimental results has been calculated. The correlation is analysed individually for each tested columns (see Fig. 18) and also for all test results (see Fig. 19). From an analysis of the results, from the uniaxial results the proposals of Kowalsky [25], Priestley [16] and Priestley et al. [17] present a better correlation to the experimental results $(R>0.7)$, as represented in Fig. 20 .

From the comparative analysis of the results in Figs. 18 and 19 it was observed that apart from the expression proposed by Gulkan and Sozen [24] and Lu et al. [27], the others give a correlation factor for the overall tests similar to the average of the correlation factor obtained for each individual test. This is justified by the 
Table 2

Best fit logarithmic curve for global damping for tested each column.

\begin{tabular}{|c|c|c|c|c|}
\hline & & & Best fit curve & $R^{2}$ \\
\hline $20 \times 40$ & $\begin{array}{l}\text { P01-N01 } \\
\text { P02-N02 } \\
\text { P12-N03 } \\
\text { P12-N04 }\end{array}$ & $\begin{array}{l}X \\
Y \\
X \\
Y \\
X \\
Y\end{array}$ & $\begin{array}{l}\xi_{\text {eq }}=8.17 \ln (\mu)+6.25 \\
\xi_{\text {eq }}=3.08 \ln (\mu)+13.09 \\
\xi_{\text {eq }}=6.41 \ln (\mu)+8.65 \\
\xi_{\text {eq }}=3.14 \ln (\mu)+12.64 \\
\xi_{\text {eq }}=5.79 \ln (\mu)+8.92 \\
\xi_{\text {eq }}=1.28 \ln (\mu)+9.19\end{array}$ & $\begin{array}{l}0.94 \\
0.54 \\
0.92 \\
0.39 \\
0.89 \\
0.14\end{array}$ \\
\hline $30 \times 40$ & $\begin{array}{l}\text { P01-N05 } \\
\text { P02-N06 } \\
\text { P12-N07 } \\
\text { P12-N08 } \\
\text { P12-N17 }\end{array}$ & $\begin{array}{l}X \\
Y \\
X \\
Y \\
X \\
Y \\
X \\
Y\end{array}$ & $\begin{array}{l}\xi_{\text {eq }}=6.96 \ln (\mu)+6.01 \\
\xi_{\text {eq }}=4.55 \ln (\mu)+9.32 \\
\xi_{\text {eq }}=7.451 \ln (\mu)+10.39 \\
\xi_{\text {eq }}=3.44 \ln (\mu)+9.49 \\
\xi_{\text {eq }}=6.16 \ln (\mu)+16.83 \\
\xi_{\text {eq }}=3.73 \ln (\mu)+18.68 \\
\xi_{\text {eq }}=12.17 \ln (\mu)+12.14 \\
\xi_{\text {eq }}=9.49 \ln (\mu)+7.61\end{array}$ & $\begin{array}{l}0.84 \\
0.57 \\
0.86 \\
0.56 \\
0.58 \\
0.42 \\
0.64 \\
0.61\end{array}$ \\
\hline $30 \times 50$ & $\begin{array}{l}\text { P12-N09 } \\
\text { P12-N10 } \\
\text { P12-N11 } \\
\text { P12-N12 } \\
\text { P12-N18 }\end{array}$ & $\begin{array}{l}X \\
Y \\
X \\
Y \\
X \\
Y \\
X \\
Y\end{array}$ & $\begin{array}{l}\xi_{\text {eq }}=6.06 \ln (\mu)+6.88 \\
\xi_{\text {eq }}=7.03 \ln (\mu)+7.23 \\
\xi_{\text {eq }}=8.57 \ln (\mu)+5.85 \\
\xi_{\text {eq }}=4.86 \ln (\mu)+7.41 \\
\xi_{\text {eq }}=7.51 \ln (\mu)+14.49 \\
\xi_{\text {eq }}=10.43 \ln (x)+15.13 \\
\xi_{\text {eq }}=5.83 \ln (\mu)+14.23 \\
\xi_{\text {eq }}=11.50 \ln (\mu)+0.679\end{array}$ & $\begin{array}{l}0.85 \\
0.95 \\
0.89 \\
0.81 \\
0.81 \\
0.82 \\
0.46 \\
0.75\end{array}$ \\
\hline $30 \times 30$ & $\begin{array}{l}\text { P01-N13 } \\
\text { P12-N14 } \\
\text { P12-N15 } \\
\text { P12-N16 }\end{array}$ & $\begin{array}{l}X \\
X \\
Y \\
X \\
Y \\
X \\
Y\end{array}$ & $\begin{array}{l}\xi_{\text {eq }}=6.15 \ln (\mu)+11.83 \\
\xi_{\text {eq }}=9.39 \ln (\mu)+7.62 \\
\xi_{\text {eq }}=9.98 \ln (\mu)+3.57 \\
\xi_{\text {eq }}=10.04 \ln (\mu)+19.25 \\
\xi_{\text {eq }}=8.18 \ln (\mu)+15.48 \\
\xi_{\text {eq }}=3.465 \ln (\mu)+21.86 \\
\xi_{\text {eq }}=9.42 \ln (\mu)+8.37\end{array}$ & $\begin{array}{l}0.96 \\
0.89 \\
0.79 \\
0.69 \\
0.87 \\
0.31 \\
0.75\end{array}$ \\
\hline $30 \times 50$ & $\begin{array}{l}\text { P12-N19 } \\
\text { P12-N20 }\end{array}$ & $\begin{array}{l}X \\
Y \\
X \\
Y\end{array}$ & $\begin{array}{l}\xi_{\text {eq }}=10.41 \ln (\mu)+6.42 \\
\xi_{\text {eq }}=1.95 \ln (\mu)+12.05 \\
\xi_{\text {eq }}=6.51 \ln (\mu)+7.59 \\
\xi_{\text {eq }}=4.53 \ln (\mu)+7.99\end{array}$ & $\begin{array}{l}0.87 \\
0.19 \\
0.80 \\
0.69\end{array}$ \\
\hline $30 \times 40$ & $\begin{array}{l}\text { P12-N21 } \\
\text { P12-N22 }\end{array}$ & $\begin{array}{l}X \\
Y \\
X \\
Y\end{array}$ & $\begin{array}{l}\xi_{\text {eq }}=5.64 \ln (\mu)+10.94 \\
\xi_{\text {eq }}=4.59 \ln (\mu)+8.81 \\
\xi_{\text {eq }}=7.31 \ln (\mu)+14.78 \\
\xi_{\text {eq }}=6.39 \ln (\mu)+15.61\end{array}$ & $\begin{array}{l}0.74 \\
0.52 \\
0.59 \\
0.54\end{array}$ \\
\hline
\end{tabular}

higher dispersion between the correlation factors obtained from both expressions for each individual test.

\subsection{Equivalent biaxial damping}

The equivalent damping was computed for each biaxial test, as a function of the effective damping estimated for each independent direction weighted with the respective potential energy, given by Eq. (16)

$\xi_{e q}=\frac{\xi_{x} \cdot E_{x}+\xi_{y} \cdot E_{y}}{E_{x}+E_{y}}$

where $\xi_{e q}$ is the equivalent damping of the biaxial response, $\xi_{x}$ and $\xi_{y}$ are the equivalent damping estimated for each individual direction $\left(X\right.$ and $Y$ ) and $E_{x}$ and $E_{y}$ are the potential energy in each direction.

In Fig. 21, the global equivalent damping obtained, according to the given methodologies, are illustrated for each load path type. The empirical expressions with better correlation to the uniaxial test results are also highlighted. From the analysis of Fig. 21, the following can be concluded:

- The estimated equivalent global damping for biaxial tests is clearly dependent on the load path. For example, for a ductility factor of 2 the rhombus load path has an equivalent damping of around of $10 \%$, while quadrangular and circular paths have an equivalent damping of $20 \%$.

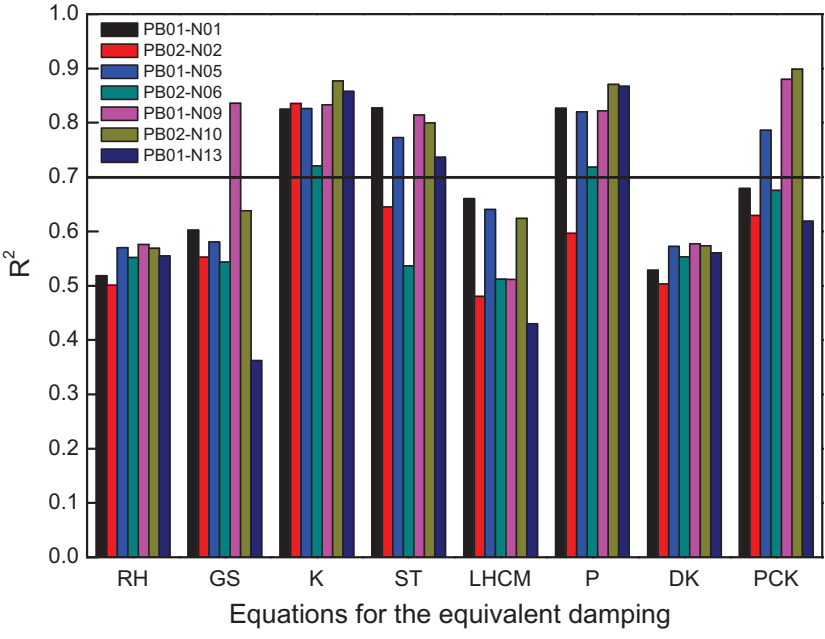

Fig. 18. R2 results for the equation proposals for equivalent damping and each uniaxial test result (Legend: RH - Rosenblueth and Hererra [23]; GS - Gulkan and Sozen; K - Kowalsky [25]; ST - Stojadinovic and Thewalt [26]: LHCM - Lu et al. [27]; P - Priestley [16]; DK - Dwairi and Kowalsky [28]; PCK - Priestley et al. [17]).

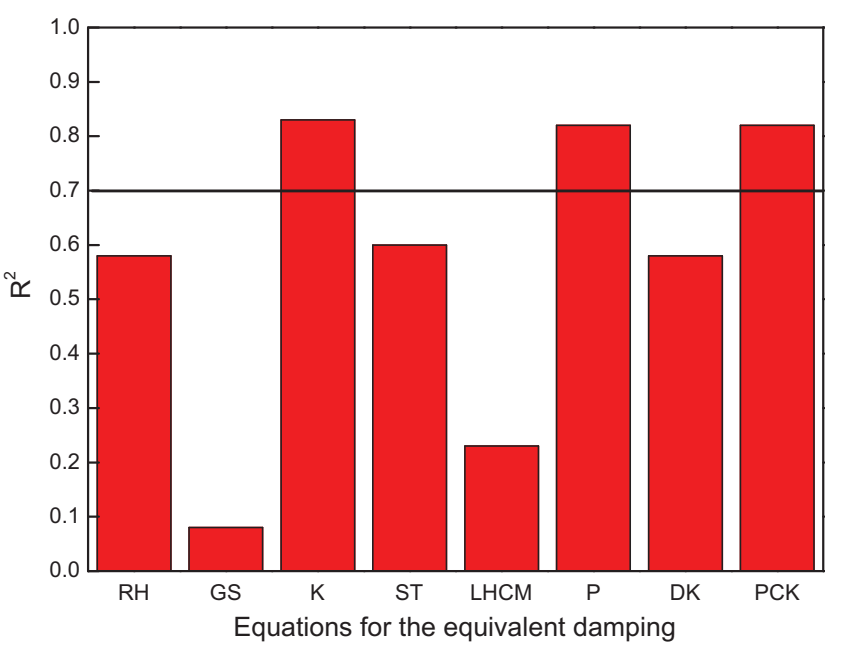

Fig. 19. R2 results for the equation proposals for equivalent damping and all uniaxial test result (Legend: RH - Rosenblueth and Hererra [23]; GS - Gulkan and Sozen; K - Kowalsky [25]; ST - Stojadinovic and Thewalt [26]: LHCM - Lu et al. [27]; P - Priestley [16]; DK - Dwairi and Kowalsky [28]; PCK - Priestley et al. [17]).

- Comparing the results obtained for uniaxial and biaxial load paths, the cruciform and rhombus paths presents similar equivalent global damping. However, the quadrangular and circular paths present higher levels of damping when compared to that obtained from the uniaxial tests. For example, for a ductility factor of 6 the uniaxial load paths induce an equivalent damping of around $20 \%$, while for the quadrangular an equivalent damping of around $30 \%$ is observed.

From the previous comments, it is concluded that the typically used equations to estimate equivalent damping for uniaxial stress cannot be used for equivalent damping in biaxial loading conditions. However, for displacement biaxial paths close to the cruciform and rhombus the empirical equations present acceptable results.

Fardis and Panagiotakos [29], from an analysis of test results of 46 columns, have confirmed that biaxial loading achieves higher values of hysteretic damping when compared to uniaxial loading. Bousias et al. [8] stated that the higher damping observed for 


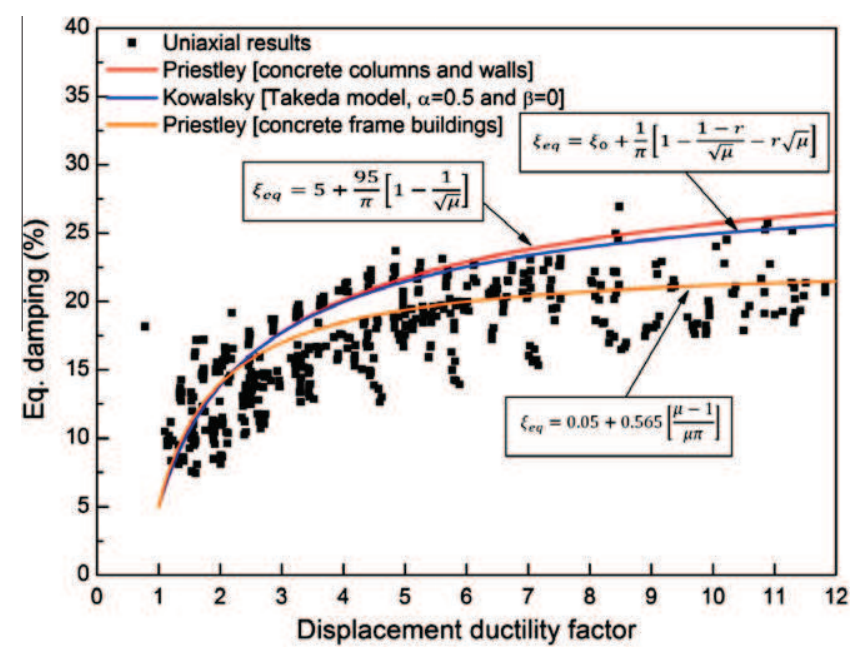

Fig. 20. Equivalent damping estimated with empirical expressions and results for all uniaxial tests.

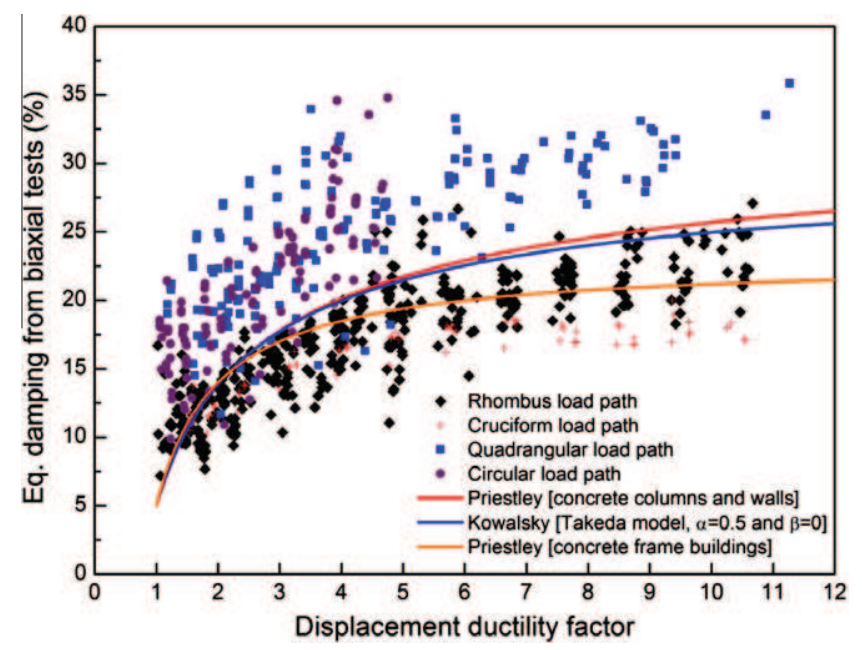

Fig. 21. Equivalent damping for biaxial tests.

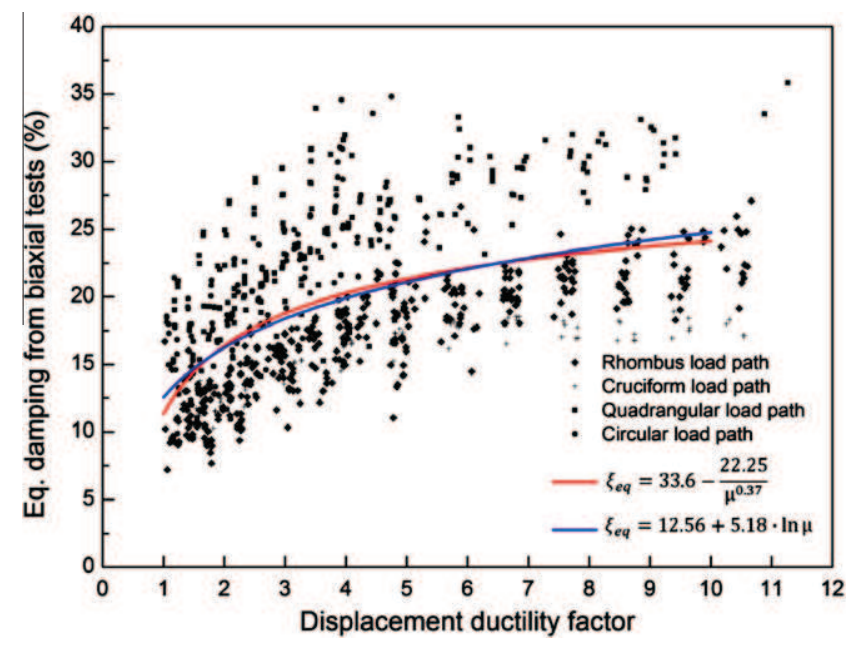

Fig. 22. Best fitted proposals for biaxial equivalent damping. biaxial loading is attributed to the coupling response of the columns between the two transverse directions.

Even if recognised the expressive dispersion of the viscous damping calculated from biaxial tests, were adjusted, by fitting the experimental data, different equations. The two best-fitting equations found are presented in Fig. 22 (Expressions 17 and 18). Both equations have a correlation factor relative to the experimental results $\left(R^{2}\right)$ of 0.31 .

$\xi_{\text {eq }}=33.6-\frac{22.25}{\mu^{0.37}}$

$\xi_{\text {eq }}=12.56+5.18 \cdot \ln \mu$

The low correlation factor found, justified by the dispersion of the equivalent damping determined from biaxial tests, is particularly dependent on the load path. However, the proposed equation can be considered as a first estimation of the equivalent damping for RC columns under biaxial loading.

\section{Conclusions}

An experimental campaign was carried out on 24 RC columns with different geometries and reinforcement, subjected to uniaxial and biaxial horizontal displacement paths combined with constant axial load and focusing on the study of the energy dissipation evolution and damping capacity. Based on the results, the following conclusions can be drawn:

- It was observed that biaxial loading can introduce higher energy dissipation (circular, rhombus and cruciform load paths) than uniaxial loading, as previously recognised by other authors. It was confirmed that the energy dissipation also depends on the column's geometry. For a specific imposed maximum drift, among the load paths considered in this study, the circular path was shown to be the most dissipative and the quadrangular load path the less dissipative. The quadrangular load path dissipates even less energy for a certain drift demand than the sum of the dissipated energy in two independent unidirectional tests for the corresponding drift level.

- In the first cycle of each peak displacement level, higher energy dissipation is observed than in the subsequent cycles for the same peak displacement. This effect is more pronounced in the biaxial loading tests. After reaching the conventional rupture of the column, the energy dissipated exhibits a deceleration.

- The cross-section geometry, axial load ratio and number of cycle repetitions has a significant influence on the total energy dissipation.

- As stated by other authors, in the square columns tested with an axial load stress of $2.33 \mathrm{MPa}$, the total dissipated energy is independent of the loading path. But for the tested square columns with higher axial load stress (7.33 MPa), it was verified that the total dissipated energy depends on the load path.

- An expression relating the RC element's displacement ductility and normalised dissipated energy was proposed for columns subjected to uniaxial or biaxial loading and constant axial force, giving, for example, for a displacement ductility of 4 a corresponding normalised dissipated energy of about 12 .

- From the analysis of the viscous damping of each independent direction of columns when tested biaxially, a larger dispersion of the damping in each direction was found.

- However, it was verified that the viscous damping highly depends on the biaxial load path. The repetition of cycles, for the same maximum displacement level, has practically no influence on the equivalent damping. 
- Different proposals, already available in the literature, for the prediction of equivalent damping of RC columns under uniaxial loading were compared with the experimental results obtained from the uniaxial tests, showing that some of these expressions do not adequately represent the results obtained.

- The equivalent biaxial damping was computed with the results of each biaxial test, presenting a huge dispersion. The equivalent biaxial damping is highly dependent on the load path.

- Two simplified expressions were proposed, based on the experimental results, allowing a rough estimation of the equivalent biaxial damping in RC columns subjected to biaxial loading. Even recognizing a possible overestimation of the equivalent damping with the adopted calculation method, these equations represent a first attempt for estimating the equivalent damping of columns under biaxial loading. However, these expressions should be corrected based on results from non-linear time history analysis and/or dynamic shaking table tests.

A large number of questions are still open concerning the biaxial behaviour of RC columns, especially regarding equivalent viscous damping associated with loading path. In the present work, the expressions proposed relating the normalised dissipated energy and equivalent biaxial damping with displacement ductility constitutes a preliminary step towards this goal. However these expressions need to be checked against additional experimental results. Even so, the research work reported is expected to contribute towards a better understanding of the biaxial response of RC columns and for the calibration of suitable numerical models for the representation of the biaxial lateral response of reinforced concrete columns under cyclic loading reversals.

\section{Acknowledgments}

The authors acknowledge to the LESE laboratory staff, particularly Valdemar Luís, André Martins and Eng ${ }^{\circ}$ Luís Noites, for all the support in the preparation and implementation of the testing set-up. This paper reports research developed under financial support provided by "FCT - Fundação para a Ciência e Tecnologia", Portugal, namely through the Ph.D. grants of the first author with reference SFRH/BD/63032/2009, and through the research project PTDC/ECM/102221/2008.

\section{References}

[1] CEB RC frames under earthquake loading, Lausanne Bulletin 220, 1996.

[2] Rodrigues, H, Arêde A, Varum H, Costa AG. Experimental study on the biaxial bending cyclic behaviour of RC columns. In: Presented at the 14th European conference on earthquake engineering. Ohrid, Republic of Macedonia, 2010.
[3] Elmenshawi A, Brown T. Hysteretic energy and damping capacity of flexural elements constructed with different concrete strengths. Eng Struct 2010;32:297-305

[4] Eom T-S, Park H-G. Evaluation of energy dissipation of slender reinforced concrete members and its applications. Eng Struct 2010;32:2884-93.

[5] Lu B, Silva PF. Estimating equivalent viscous damping ratio for RC members under seismic and blast loadings. Mech Res Commun 2006;33:787-95.

[6] Shibata A, Sozen MA. Substitute-structure method for seismic design in R/C. J Struct Div, vol. ASCE, 1976.

[7] Blandon C. Equivalent viscous damping equations for direct displacement based design. master. Rose School, Pavia, 2004.

[8] Bousias SN, Verzeletti G, Fardis MN, Gutierrez E. Load-path effects in column biaxial bending with axial force. J Eng Mech 1995:596-605.

[9] Qiu F, Li W, Pan P, Qian J. Experimental tests on RC columns under biaxial quasi-static loading. Engrg Struct 2002;24:419-28.

[10] Ohno T, Nishioka T. An experimental study on energy absorption capacity of columns in reinforced concrete structures. Proc JSCE Struct Eng/Earthquake Eng 1984;1(2):137-47.

[11] Tsuno K, Park R. Experimental study of reinforced concrete bridge piers subjected to bi-directional quasi-static loading. Struct Engrg Struct JSCE 2004;21(1):11s-26s.

[12] Park YJ, Ang HS. Seismic damage model for reinforced concrete. ASCE - J Struct Eng 1985;111(4):722-39.

[13] Nmai CK, Darwin D. 1984. Cyclic behavior of lightly reinforced concrete beams. University of Kansas Centre for Research, SM report no. 12.

[14] Darwin D, Nmai CK. Energy dissipation in RC beams under cyclic load. J Struct Eng 1986;112:1829-46.

[15] ACI318-08 - Building code requirements for structural concrete (ACI 318-08) and commentary (ACI 318R-08), ed. USA: American Concrete Institute; 2008.

[16] Priestley MJN. Displacement-based seismic assessment of reinforced concrete buildings. J Earthquake Eng Imperial College Lond 1997;1:157-92.

[17] Priestley MJN, Calvi GM, Kowalsky MJ. Direct displacement-based seismic design of structures. Pavia: IUSS Press; 2007.

[18] Otani S. Hysteresis models of reinforced concrete for earthquake response analysis. J Faculty Eng 1981;36(2):407-41.

[19] Priestley MJN, Grant DN, Blandon CA. Direct displacement-based seismic design. In: Presented at the proceedings of the New Zealand society for earthquake engineering conference. Wairakei, New Zealand, 2005.

[20] Jacobsen LS. ASME Trans 1930;52:169-81 [Steady forced vibrations as influenced by damping].

[21] Varum H. Seismic assessment, strengthening and repair of existing buildings, Ph.D. thesis. Aveiro: Civil Engineering Department, University of Aveiro; 2003.

[22] Dwairi HM, Kowalsky MJ, Nau JM. Equivalent damping in support of direct displacement-based design. J Earthquake Eng 2007;11:512-30. 2007/07/30.

[23] Rosenblueth E, Herrera I. On a kind of hysteretic damping. J Eng Mech Division ASCE 1964;90:37-48.

[24] Gulkan P, Sozen MA. Inelastic responses of reinforced concrete structures to earthquakes motions. In: Proceedings of the ACI, vol. 71(12), 1974.

[25] Kowalsky MJ. Displacement based design - a methodology for seismic design applied to RC bridge columns, Master's thesis. San Diego, CA: University of California; 1994.

[26] Stojadinovic B, Thewalt CR. Energy balanced hysteresis models. College of Engineering, University of California at Berkeley, 1996.

[27] Lu Y, Hao H, Carydis PG, Mouzakis H. Seismic performance of RC framesdesigned for three different ductility levels. Eng Struct 2001;25:537-47.

[28] Kowalsky MJ, Dwairi H. Investigation of Jacobsen's equivalent viscous damping approach as applied to displacement-based seismic design. In: Presented at the proceedings of the 13th world conference on earthquake engineering. Vancouver, Canada, 2004.

[29] Fardis M, Panagiotakos T. Hysteretic damping of reinforced concrete elements. In: Presented at the 11th world conference on earthquake engineering, Acapulco, Mexico, 1996. 